\title{
Chapter 5 \\ Legal Linked Data Ecosystems and the Rule of Law
}

\begin{abstract}
This chapter introduces the notions of meta-rule of law and socio-legal ecosystems to both foster and regulate linked democracy. It explores the way of stimulating innovative regulations and building a regulatory quadrant for the rule of law. The chapter summarises briefly (i) the notions of responsive, better and smart regulation; (ii) requirements for legal interchange languages (legal interoperability); (iii) and cognitive ecology approaches. It shows how the protections of the substantive rule of law can be embedded into the semantic languages of the web of data and reflects on the conditions that make possible their enactment and implementation as a socio-legal ecosystem. The chapter suggests in the end a reusable multi-levelled meta-model and four notions of legal validity: positive, composite, formal, and ecological.
\end{abstract}

Keywords Web of data - Socio-legal ecosystem $\cdot$ Rule of law $\cdot$ Meta-rule of law Semantic languages · Governance $\cdot$ Linked democracy $\cdot$ Semantic web regulatory models $\cdot$ Regulatory quadrant $\cdot$ Legal validity

\subsection{Introduction: The Rule of Law in a New Brave World}

We will expand in this chapter some ways of implementing linked democracy on legal and political bases. Linked democracy is not only a theoretical approach incorporating open linked data to theories of democracy. It consists of practices and the real behaviour of people exercising their political rights on everyday bases. Thus, it also possesses a personal and cultural dimension that should be valued and protected. Law is an obvious element. Behaviour on the web should be 'fair' and 'legal'. What does it mean? Different states have different jurisdictions, and despite the international trends of the global market, law has been, and still is, dependent on national states.

How could we incorporate regulatory forms of empowering people on the web? How could algorithmic governance, data analytics, and semantics be used to foster the principles of linked democracy that we have just presented at the end of Chap. 4 ? 
We will contend that there are two ways to reach such objectives: (i) embedding the principles of the substantive rule of law into the web of linked data (what we will call the meta-rule of law), and (ii) incentivising the creation of socio-legal ecosystems, i.e. the social conditions that are required to implement the meta-rule of law online and outline them among all stakeholders and users.

We admit that this can be easier said than done. These two objectives might have an idealistic flavour. A few corporations have a dominant position on the web, they can trade and invade privacy, and they usually do. As Shadbolt and Hampson (2018) have nicely put it, we live in a hyper-complex environment, shaped by our own tools. This is a good breeding ground for elites to thrive. They also point out that "what has changed is human potential, thanks to our transformative new tools. [...] The point is not that machines might wrest control from the elites. The problem is that most of us might never be able to wrest control of the machines from the people that occupy the command posts" (Shadbolt and Hampson 2018, 63).

Power is certainly a problem. In our hyper-connected world, we barely know in advance what will come next. But there are protections to be put in place, and rights and duties to be implemented. Some of them differ depending on the country and legal culture. For instance, the common law version of the rule of law is not completely equivalent to its civil law counterpart, more top-down (stepwise) designed, and connected to the structure of the state [Rechtsstaat, Etat de droit, Stato de diritto, Estado de derecho]. There also are striking dissimilarities related to the meaning and the scope of rights (what is meant by the content of rights). For instance, privacy and data protection are considered fundamental rights in Europe, but not in the USA. This affects the level of protection.

Empowering people seems to be the first step to shelter them from democratic erosion. We have drawn in Table 5.1 a raw alignment of the rights and protections of the substantive rule of law ${ }^{1}$ to the linked democracy properties and principles of Ostrom's Common-Pool Resources (CPR) that we have already introduced at the end of Chap. 4.

This table is what a lawyer is expected to do. Freedom and liberty are pre-conditions for all rights. However, our hyper-connected world is no longer the world we had known before. Enhancing rights and making officers and citizens compliant within a commonly shared regulatory framework constitutes another challenge that we know in advance will not be accomplished in the short run.

Law and Society scholars have highlighted the obstacles that hamper the social and political uptake of the rule of law - the "unrule of law" or "rule by law" in totalitarian regimes, the use of a "regulatory rule of law" as a liberal strategy to contrive a transnational global order, and rule of law abuses in Western states. ${ }^{2}$

\footnotetext{
${ }^{1}$ According to Tamanaha $(2004,2009,2011)$ there is a "thin" or "formal" definition of rule of law — set forth in advance, public, general, clear, stable and certain, and applied to everyone according to its terms - and a more substantive one "embracing fundamental rights, democracy, and/or criteria of justice". See also Carothers (1998).

${ }^{2}$ See Ginsburg and Tamir (2008), Gel'man (2004), Uildriks (2010), Cheesman (2015), Merry (2017), Taylor (2017), Abel (2018).
} 
Table 5.1 Alignment of LD properties and CPR Principles with the Rule of Law

\begin{tabular}{|c|c|c|}
\hline Contextually bounded & CPR principles & Rule of law principles \\
\hline (i) Contextually bounded & $\begin{array}{l}\text { 1. Clearly defined [user and } \\
\text { resource] boundaries }\end{array}$ & I. Right to assemble \\
\hline (ii) Open ended & $\begin{array}{l}\text { 2. Rules in use matched to local } \\
\text { needs and conditions; } \\
\text { [congruence between } \\
\text { appropriation and provision } \\
\text { rules, or benefits and costs] }\end{array}$ & $\begin{array}{l}\text { II. Rules in use matched to the } \\
\text { protections and boundaries of } \\
\text { the rule of law, privacy, and } \\
\text { data protection }\end{array}$ \\
\hline (iii) Blended & $\begin{array}{l}\text { 3. Individuals affected by these } \\
\text { rules usually participating in } \\
\text { modifying the rules }\end{array}$ & $\begin{array}{l}\text { III. Rights of voting and free } \\
\text { speech }\end{array}$ \\
\hline (iv) Distributed & $\begin{array}{l}\text { 4. System for self-monitoring } \\
\text { members' behaviour [and } \\
\text { resource monitoring] }\end{array}$ & $\begin{array}{l}\text { IV. Right of self-regulation; } \\
\text { privacy, and data protection }\end{array}$ \\
\hline (v) Technology-agnostic & $\begin{array}{l}\text { 5. Graduated system of } \\
\text { sanctions }\end{array}$ & $\begin{array}{l}\text { V. Right of self-regulation; } \\
\text { privacy and data protection }\end{array}$ \\
\hline (vi) Modular & $\begin{array}{l}\text { 6. Access to low-cost } \\
\text { conflict-resolution mechanisms }\end{array}$ & VI. Access to justice \\
\hline (vii) Scalable & $\begin{array}{l}\text { 7. Right of community } \\
\text { members to devise their own } \\
\text { rules respected by external } \\
\text { authorities }\end{array}$ & $\begin{array}{l}\text { VII. Sovereignty, checks and } \\
\text { balance of powers, and free } \\
\text { speech }\end{array}$ \\
\hline (viii) Knowledge-reusing & $\begin{array}{l}\text { 8. Nested enterprises (multiple } \\
\text { layers) }\end{array}$ & $\begin{array}{l}\text { VIII. Right to education and } \\
\text { access to knowledge } \\
\text { (innovation); privacy and data } \\
\text { protection }\end{array}$ \\
\hline (ix) Knowledge-archiving & & $\begin{array}{l}\text { IX. Right to education and } \\
\text { access to knowledge } \\
\text { (innovation); privacy and data } \\
\text { protection }\end{array}$ \\
\hline (x) Aligned & & X. Legal compliance \\
\hline
\end{tabular}

Notwithstanding this, the positive side and protections of the rule of law are deemed to transcend the boundaries of national states to become a general paradigm, an institutional ideal to be embedded into the making of markets, institutions, and human relationships at a global level (Palombella 2009, 2010).

We can assume this ideal, under two conditions. First, we should treat it is as a design ideal, not as a fact (i.e. as a series of principles to be nested into the Internet and the Web through the algorithms and the languages of the Web of Data). Second, we should be able to make compatible two competing legal theories of law and regulation operating since the 20th century, namely, formal (jurisprudential) 


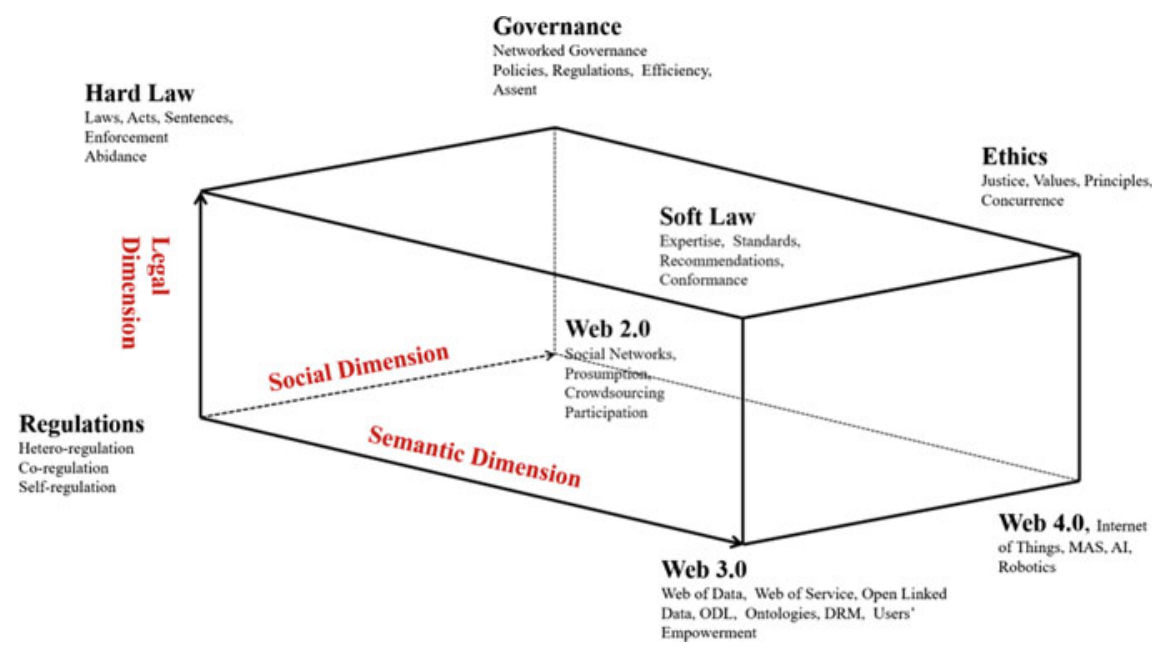

Fig. 5.1 Dimensions of regulatory models

and empirical (sociological) approaches to regulations. ${ }^{3}$ This is another ideal that has not yet been completely reached, and whose complexity should not be underestimated.

Figure 5.1 depicts a preliminary general framework in which regulations (including hetero-, co-, and self-regulations) (i) coexist with new instruments of social and political governance on the Web; (ii) are created, implemented and eventually enforced through three regulatory dimensions: legal, social, and linguistic (Web languages); (iii) and are embedded into regulatory models which take into account the "hybrid" interface between human and machines across the Web, the social Web (2.0) and the Web of Data (3.0). It is still preliminary, but the next step seems to be the Intelligent Web (4.0), connecting the Internet of Things, Multi-Agent Systems (MAS), and blockchain technologies with linked and big data-also called Cyber-physical systems (CPS) (Xu et al. 2018). It is worth noting that policies, standards and, especially, ethics and values embedded into the systems are expected to play an increasing regulatory role in this new environment. End-users have always been a primordial orientation for semantic web developers (d'Aquin et al. 2008; Domingue et al. 2014). ${ }^{4}$

A few cautionary notes are worth mentioning: (i) the political nature of the rule of law must not be forgotten (the identities and boundaries of individuals, self-constituted social groups, and communities raise different problems of

\footnotetext{
${ }^{3}$ See on the "new realism" "which aims selfconsciously to theorize the bridge between the world and legal institutions without reducing one to the other", Nourse and Shaffer (2009). See also Selznick (2003), Erlanger et al. (2005), Macauley (2005), Miles and Sunstein (2008).

${ }^{4}$ Cfr. Re-Coding Black Mirror Workshops, e.g. Troullinou et al. (2018). See also Taylor and Boniface (2017), EU H2020 Project e-Sides, https://e-sides.eu/e-sides-project.
} 
sovereignty); (ii) principles and values cannot be fully modelled and embedded into computer systems $^{5}$ (as the present attempts to code Privacy by Design show) ${ }^{6}$; (iii) the list of legal principles is not exhaustive, and many of them can be combined and applied at every layer of the table (Fig. 5.1); and (iv) there are so many jurisdictions and policies-from constitutional issues to intellectual property, tort law, security and data protection - that it is currently impossible to deal with all specific legal regimes of the web of data at the same time. ${ }^{7}$

Web 3.0 - in short, the web of data on the Internet - is constituted by a myriad of languages enacted by the users who produce, use, transform, trade, operate, and interact performing legal and political acts. ${ }^{8}$ How might this behaviour be regulated? How can the protections of the meta-rule of law be implemented in this brave new world?

We should first distinguish between systemic and semantic interoperability. Second, we should consider the insights of cognitive science on how artificial agency and human action can be coordinated to attain collective goals. Third, we should merge legal and political governance, now in separate silos. Fourth, we should re-conceptualise regulatory and legal compliance according to these guidelines. And finally, we could suggest a meta-model bringing all these elements together.

\subsection{Governing Linked Democracy: Interoperable and Legal Governance}

\subsubsection{Semantic and Systemic Interoperability}

Semantic interoperability refers to the creation of a common meaning for information exchange across computational systems. Systemic interoperability points at the ability of complex systems to interact, share, and exchange information. The latter focuses on the coordination of practices, including human behaviour, organisational structures, tools, languages, and techniques (Kun et al. 2008; Mathews 2017; Casanovas et al. 2017b). Both dimensions should be analytically distinguished for a co-integration of the computational and social dimensions into the specific ecosystems created through this mutual interface.

\footnotetext{
${ }^{5}$ Cfr. Li (2012), esp. Koops and Leenes (2014), Koops et al. (2016).

${ }^{6}$ See the results of the W3C Workshop on Privacy organised by R. Wennig and S. Kirrane, https:// www.w3.org/2018/vocabws/report.html.

${ }^{7}$ We carried out a preliminary analysis for Europe in Rodríguez-Doncel et al. (2016).

${ }^{8}$ The Web 2.0 includes services, platforms and applications, end-users, prosumers (both producers and consumers of information), citizens, and social networks that constitute the grassroots of the new digital neighbourhood. The Web 3.0 includes the methods, languages and computer devices that allow turning content - the information spread over the web - into structured information, that is, into shareable and reusable knowledge.
} 
Computer science and society co-evolve in intertwined ways. From this perspective, we can also distinguish between computational requirements and social (behavioural, organisational) conditions. Computational requirements focus on the description of computationally tractable elements in some language. For example, object-oriented analysis applies object-oriented programming and visual modelling through development lifecycles. Goal-oriented requirements engineering "is concerned with the use of goals for eliciting, elaborating, structuring, specifying, analysing, negotiating, documenting, and modifying requirements" (van Lamsweerde 2001, 2009). Both techniques stress the relationship with end-users and stakeholders to enrich the knowledge acquisition process.

Social conditions imply an empirical description and a theoretical account of social issues, statuses, and conflicts. Turning them into modelling requirements is a non-trivial task of a theoretical nature. ${ }^{9}$ It refers to what E. Feingenbaum called "the knowledge acquisition bottleneck" (Feingenbaum 1982), and R. Hoekstra "the knowledge reengineering bottleneck" (Hoekstra 2010). As Hoekstra is suggesting, the rapid increase of linked data poses new challenges for the whole Semantic Web project at the cost of control. Knowledge reuse is more de-contextualised now, and ontology building methodology is becoming more complex as users participate and expert knowledge is diversified, scaling up to more complex forms of cooperation between experts and citizens (Corcho et al. 2015). ${ }^{10}$ Citizen science, crowdsourced people's participation in scientific endeavours, is gaining strength and posing more challenges too, i.e. the role that volunteers play in true collaborative co-creation processes at all stages of the scientific design (Celino et al. 2018).

From a democratic perspective, law and legal systems could be shaped in such a way to create incentives for innovation and change. Semantic interoperability between all jurisdictions in national and international legal systems is an important component; the next layer of interoperable laws, as we have shown in previous chapters. But anchoring them into different organisations and social communities poses different types of problems: it requires systemic interoperability and new forms of responsive, better and smart regulations to foster citizens' participation and community building. In a big data era, we should not lose sight of how close social bonds are built up:

[...] we risk overlooking the much more important story here, the real revolution, which is the mass democratisation of the means of access, storage and processing of data. This story isn't about large organisations running parallel software on tens of thousands of servers, but about more people than ever being able to collaborate effectively around a distributed ecosystem of information, an ecosystem of small data. (Pollock 2013)

\footnotetext{
${ }^{9}$ See the complete account edited by Motta (2013) on 25 years of knowledge acquisition research.

${ }^{10}$ Their classification (Corcho et al. 2015, 15): (i) upper-level ontology engineers (deep knowledge about formal logic and philosophy); (ii) heavyweight ontology engineers (domain experts); (iii) lightweight ontology engineers (develop vocabularies to be used in the linked data context); (iv) SKOS (Simple Knowledge Organization System) concept scheme developers (interested in developing thesauri and other types of classifications); (v) web developers contributing to Schema. org.
} 
As highlighted in Chaps. 2 and 3, the meso-level, the institutional implementation layer that is also required to operationalize linked democracy has not yet been considered in the legal domain. Linked Open Data (LOD) is being implemented, but not Linked Platforms or Linked Ecosystems (LE). The big "connectome" is still the administration. Case law and legislation identifiers, such as the European ECLI and ELI, can be situated on top. There are also serious attempts to link legal multi-lingual resources. CELLAR stores all metadata and digital content managed by EurLex, the EU Publications Office (Francesconi et al. 2015). This is the first step to generate reusable knowledge. For instance, the Law Enforcement Agency Identifiers Crosswalk (LEAIC) is a USA programme addressed to merging crime sources from cities under the county level. ${ }^{11}$ It facilitates linking reported crime data with socio-economic data. This does not hail from citizens' organisations, but from government agencies to implement criminal policies. But it facilitates more accurate studies on the use of force by the police (Garner et al. 2018).

The legal domain is a complex one, related to normative and legal theories. There is a top-down drive amongst legal scholars and computer scientists to represent its content as a whole. Thus, the requirements for rule interchange languages presented in Table 5.2 are based on concepts elaborated in normative theory (e.g. defeasibility, validity, and lifecycle of norms). LegalXML, RuleMarkup Language (RuleML), Semantics of Business Vocabulary and Business Rules (SBVR), the Semantic Web Rule Language (SWRL), the Rule Interchange Format (RIF), and the Legal Knowledge Interchange Format (LKIF) are rule interchange languages for the legal domain. ${ }^{12}$ Originally, the Rule Interchange Format (RIF) aimed to create a standard for exchanging rules among rule systems. In contrast to other SW standards (such as RDF, OWL and SPARQL) it was clear that a single language would not cover all paradigms for using knowledge in knowledge representation and business modelling (WWW 2013), although the media of exchange between different rule systems is XML. ${ }^{13}$

Gordon et al. (2009) conceptualised ten years ago the main legal components as requirements that rule interchange languages needed to comply with. Yet, they also highlighted that there is no language able to satisfy all of them simultaneously. Table 5.2 summarises their results. ${ }^{14}$

This framework was grounded on a positivistic approach, but it addressed new problems and challenged what 'law architecture' or 'legal system' had meant so far, at every layer of the table. Legal drafting, ruling and contracting are still activities carried out through natural languages, and so are legal outcomes. As noticed by Lam et al. (2016), even from this perspective, there are problems with handling the

\footnotetext{
${ }^{11}$ https://www.icpsr.umich.edu/icpsrweb/ICPSR/studies/35158/datadocumentation.

${ }^{12}$ See Casanovas et al. (2016) for the state of the art for web semantics in the legal domain.

${ }^{13}$ See the WWW RIF Overview (second version, February 2013) at https://www.w3.org/2013/pdf/NOTE-rif-overview-20130205.pdf.

${ }^{14}$ The content of the table is reproduced slightly modified in Balke et al. (2013). The authors explicitly assert that these aspects "contribute to classifying norms and can be extended to other normative domains besides the law".
} 
Table 5.2 Requirements for rule interchange languages

\begin{tabular}{|c|c|}
\hline 1. Isomorphism & $\begin{array}{l}\text { A one-to-one correspondence between the rules in the formal model } \\
\text { and the units of natural language text which express the rules in the } \\
\text { original legal sources }\end{array}$ \\
\hline 2. Reification & $\begin{array}{l}\text { Rules are objects with properties: } \\
\text { a) Jurisdiction: limits where the rule is authoritative, and its effects } \\
\text { are binding } \\
\text { b) Authority: ranking status of the rule within the sources of law } \\
\text { (constitutional rule, or statute...) } \\
\text { c) Temporal properties: (i) time when the norm has been enacted, } \\
\text { (ii) time when the norm can produce legal effects, (iii) time when } \\
\text { the normative effects hold }\end{array}$ \\
\hline 3. Rule semantics & $\begin{array}{l}\text { Semantics allows for correctly computing the legal effects that } \\
\text { should follow }\end{array}$ \\
\hline 4. Defeasibility & $\begin{array}{l}\text { When the antecedent of a rule is satisfied by the facts of a case, the } \\
\text { conclusion of the rule presumably holds, but is not necessarily } \\
\text { true). Defeasibility breaks down into: } \\
\text { a) Conflicts (rules may lead to incompatible legal effects): (i) one } \\
\text { rule is the exception of the other, (ii) rules have different ranking } \\
\text { status, (iii) rules have been enacted at different times. } \\
\text { b) Exclusionary rules (some rules provide one way to explicitly } \\
\text { undercut other rules, namely, to make them inapplicable) }\end{array}$ \\
\hline 5. Contraposition & $\begin{array}{l}\text { If some conclusion of a rule is not true, the rule does not sanction } \\
\text { any inferences about the truth of its premises }\end{array}$ \\
\hline $\begin{array}{l}\text { 6. Contributory reasons } \\
\text { or factors }\end{array}$ & $\begin{array}{l}\text { It is not always possible to formulate precise rules for aggregating } \\
\text { the factors relevant for resolving a legal issue }\end{array}$ \\
\hline 7. Rule validity & $\begin{array}{l}\text { Rules can be or become invalid. Deleting invalid rules is not an } \\
\text { option when it is necessary to reason retroactively with rules which } \\
\text { were valid at various times over a course of events: (i) the } \\
\text { annulment of a norm is usually seen as a kind of repeal which } \\
\text { invalidates the norm and removes it from the legal system as if it } \\
\text { had never been enacted (the effect of an annulment applies ex tunc: } \\
\text { annulated norms are prevented from producing any legal effects, } \\
\text { also for past events); (ii) an abrogation on the other hand operates } \\
\text { ex nunc (the rule continues to apply for events which occurred } \\
\text { before the rule was abrogated) }\end{array}$ \\
\hline 8. Legal procedures & $\begin{array}{l}\text { Rules regulate also whether or not some action or state complies } \\
\text { with other, substantive rules): (i) procedures that regulate methods } \\
\text { for detecting violations of the law, (ii) procedures that determine } \\
\text { the normative effects triggered by norm violations (reparative or } \\
\text { compensatory obligations) }\end{array}$ \\
\hline 8. Normative effects & $\begin{array}{l}\text { Such as obligations, permissions, prohibitions and also more } \\
\text { articulated effects) e.g.: } \\
\text { a) Evaluative, there is a value to be optimized or an evil to be } \\
\text { minimized } \\
\text { b) Qualificatory, which ascribe a legal quality to a person or an } \\
\text { object } \\
\text { c) Definitional, which specify the meaning of a term } \\
\text { d) Deontic, which, typically, impose the obligation or confer the } \\
\text { permission to do a certain action }\end{array}$ \\
\hline
\end{tabular}


Table 5.2 (continued)

\begin{tabular}{l|l}
\hline & $\begin{array}{l}\text { e) Potestative, which attribute powers } \\
\text { f) Evidentiary, which establish the conclusion to be drawn from } \\
\text { certain evidence } \\
\text { g) Existential, which indicate the beginning or the termination of } \\
\text { the existence of a legal entity } \\
\text { h) Norm-concerning effects, which state the modifications of norms } \\
\text { (abrogation, repeal, substitution...) }\end{array}$ \\
\hline $\begin{array}{l}\text { 9. Persistence of } \\
\text { normative effects }\end{array}$ & $\begin{array}{l}\text { Some normative effects persist over time unless some other and } \\
\text { subsequent events terminate them }\end{array}$ \\
\hline 10. Values & Some values are promoted by the legal rule \\
\hline
\end{tabular}

Simplified reconstruction, Source Gordon et al. (2009)

${ }^{a}$ Accordingly, rule conflicts have been traditionally resolved using principles about use priorities: (i) lex specialis (it gives priority to the mores specific rule), (ii) lex superior (it gives priority to the rule from the higher authority), (iii) lex posterior (it gives priority to the rule enacted later)

deontic effects that are needed in legal practice. ${ }^{15}$ For instance, the basic assumption of legal isomorphism ${ }^{16}$ is meant to bridge the gap between the contents of normative texts and the rules describing them. ${ }^{17}$ OASIS standards for LegalXML and LegalRuleML have been based on this isomorphic assumption. OASIS Legal RuleML highlights that "the legal text is the only legally binding element [our emphasis] the connection between text and the rule(s) (or fragment of rule) guarantees the provenance, authoritativeness, and authenticity of the rules modelled by the legal knowledge engineer" (Athan et al. 2015). Thus, it embraces legal hermeneutics as a fundamental set of privileged techniques to produce legal knowledge (Athan et al. 2014). ${ }^{18}$

This is a convenient assumption, but not generalizable to all possible environments and relationships between subjects, as there is no direct translation from the

\footnotetext{
${ }^{15}$ RuleML is an XML-based standard language that enables users to use different types of rules (such as derivation rules, facts, queries, integrity constraints, etc.) to represent different kinds of elements according to their needs. However, so far, "it lacks support for the use of deontic concepts, such as obligations, permissions and prohibitions, making it impossible to handle cases with contrary-to-duty (CTD) obligations (or reparational obligations), which is not uncommon in legal contracts."

${ }^{16}$ According to Palmirani et al. (2012) isomorphism is "the concept to associate any rule to its provision(s) in order: (1) to have a relationship between rule(s) and legal provision(s) that originated it/them; (2) to have a clear explanation, supported by the original legal text, to provide to the end user as outcome of the legal reasoning process (demonstration). The original legal provision is the only legal binding text; (3) to help the maintenance of the rules knowledge base when the text changes (change management)".

${ }^{17}$ Cfr. Bench-Capon and Coenen (1992), Bench-Capon and Gordon (2009). The authors contend that 'legal isomorphism' has a different function and meaning than the mathematical notion of isomorphism. They are referring to the reflection of legal content into formal languages.

${ }^{18}$ "LegalRuleML endeavours not to account for how different interpretations arise, but to provide a mechanism to record and represent them" (Athan et al. 2014).
} 
content of statutes, codes, directives, regulations and acts, to formal languages. ${ }^{19}$ From a linked ecosystem perspective, texts are only a component of the overall social system: in real settings, at the implementing and use level, meaning and cognition are distributed across the ecosystem. ${ }^{20}$ In a similar cognitive vein, after their work on MetaLex and LKIF Core, Boer (2009) criticised the bijective mapping of legal rules to logical propositions, and Hoekstra $(2009,161)$ pointed out that "the need for a language construct, such as n-ary relations should be based on a conscious decision to interpret a use case in a particular way: it is an ontological commitment." This is an important epistemic concept that should be made explicit in all modelling of social life, including legal instruments, documents, and behaviour of the legal professions.

Other modelling approaches for legal knowledge management are based on a different set of closely related concepts. RELaw Workshops have been held to discuss legal requirements since 2008, including sociological dimensions. ${ }^{21}$ However, the essential issue of how to link platforms and ecosystems is still at a preliminary stage.

There are several ways to include stakeholders into the design process, depending on the objectives of the system. Most of legal management systems are compliance-oriented, as the design is mindful of the features of legal knowledge as it is used and interpreted by lawyers, external auditors, and business analysts. They are not primarily intended to comprehend citizens' political participation, nor the features of crowd-civic systems that facilitate interaction, debate, and content creation (referred in Chap. 3, 3.4.2, Table 3.1). ${ }^{22}$ However, it has not been ruled out that they could incorporate these functions in the future, as they endorse flexible normative interpretations and end-users' participation, two of the main qualities of relational law. As we will see later, we understand relational law as the assignment, embodiment and realization of rights within a shared ecosystem; i.e. creating an aggregated value to foster trust and security in the connection between Web 2.0 and Web 3.0 (Casanovas 2013).

\footnotetext{
${ }^{19}$ See Wyner and Governatori (2013) about the challenges to be faced.

${ }^{20}$ See Hutchins $(1995,2006)$ : "The meaning of a complex emerges from the interactions among the modalities that include the body as well as material objects present in the environment. The effects of these interactions are generally not simply additive. Such a meaning complex may be built up incrementally or produced more or less whole, depending on the nature of the components and the relations among them."

${ }^{21}$ RELaw: International Workshop Series on Requirements Engineering and Law, http://gaius.isri. cmu.edu/relaw/.

${ }^{22}$ See the compatible functions between Eunomos and Legal-Urn in Boella et al. (2014). Both legal management systems encompass the discussions between different kind of stakeholders (lawyers, auditors, and business administrators).
} 


\subsubsection{Responsive, Smart, and Better Regulations}

The Communication from the Commission of 23 March 2017 defined the strategy for governance and interoperability across the state members. ${ }^{23}$ The EU has adopted a relational view to foster citizen participation, transparency, public monitoring and control, considering interoperability as a prerequisite "for enabling electronic communication and exchange of information between public administrations" and "for achieving a digital single market." (EU 2017). In this regard, the EU provides a set of principles and recommendations ${ }^{24}$ to promote electronic communication across administrations, distinguishing four layers of interoperability: (i) legal (ensuring that organisations operating under different legal frameworks, policies and strategies are able to work together, setting interoperability checks to identify legal barriers); (ii) organisational (relationships between service providers and service consumers); (iii) semantic (developing vocabularies and schemata to describe data exchanges in the same format); (iv) technical (applications and infrastructures linking systems and services). More precisely:

(i) legal issues, e.g. by ensuring that legislation does not impose unjustified barriers to the reuse of data in different policy areas; organisational aspects, e.g. by requesting formal agreements on the conditions applicable to cross-organisational interactions; data/semantic concerns, e.g. by ensuring the use of common descriptions of exchanged data; (iv) technical challenges, e.g. by setting up the necessary information systems environment to allow an uninterrupted flow of bits and bytes. [COM (2017) 134]

The European Interoperability Framework (EIF) conceptual model embraces a holistic perspective on interoperability and compliance, acknowledging the complexity of data governance. ${ }^{25}$ This is a step towards what many years ago Nonet and Selznick (1978) called responsive law: "a wider sharing of legal authority", "participatory decision as a source of knowledge, a vehicle of communication, and a foundation for consent".

We will highlight three different empirical approaches-responsive, smart, and better regulations - which are not identical, but are devoted to the objective of getting law closer to civil society. After work done by socio-legal scholars such as Selznick, Nonet and Kazan, and activists like Ralph Nader, ${ }^{26}$ the "responsive law"

\footnotetext{
${ }^{23}$ Brussels, 23.3.2017 COM (2017) 134 final. Source: https://eur-lex.europa.eu/resource.html?uri= cellar:2c2f2554-0faf-11e7-8a35-01aa75ed71a1.0017.02/DOC_1\&format=PDF.

${ }^{24}$ Underlying principles for public administration are citizen- and user-centred: (i) subsidiarity and proportionality, (ii) openness, (iii) transparency, (iv) reusability, (v) technological neutrality and data portability, (vi) user-centricity, (vii) inclusion and accessibility, (viii) security and privacy, (ix) multilingualism, (x) administrative simplification, (xi) preservation of information, (xii) assessment of effectiveness and efficiency.

${ }^{25}$ European Interoperability Framework -Implementation Strategy: https://ec.europa.eu/isa2/ sites/isa/files/eif_brochure_final.pdf.

${ }^{26} \mathrm{http}: / / \mathrm{csrl}$.org/about/.
} 
idea came into age and was fleshed out by legal sociologists and criminologists. How regulations and law should be approached if their main aim was empowering people? According to Braithwaite:

Responsive regulation involves listening to multiple stakeholders and making a deliberative and flexible (responsive) choice from regulatory strategies that can be conceptually arranged in a pyramid. At the bottom of the pyramid are more frequently used strategies of first choice that are less coercive, less interventionist, and cheaper. ${ }^{27}$

Ayres and Braithwaite (1995) showed that compliance, respect, and cooperation in implementing regulations were possible if citizens and professional people could embrace and apply them into their everyday life. So, they should be co-involved in lawmaking, deployment and even enforcement of legislation throughout the legal drafting, implementation and eventual reform process. Between state regulation and self-regulation there are many stances that are worth exploring:

Good policy analysis is not about choosing between the free market and government regulation. Nor is it simply deciding what the law should proscribe. If we accept that sound policy analysis is about understanding private regulation - by industry associations, by firms, by peers, and by individual consciences - and how it is interdependent with state regulation, then interesting possibilities open up to steer the mix of private and public regulation. It is this mix, this interplay, that works to assist or impede solution of the policy problem. (Ayres and Braithwaite 1995, 3).

Thus, democracy is enhanced and citizens are empowered by: (i) making choices to vote in the marketplace; (ii) voting rights in a representative democracy; (iii) participating "in any local area of collective decision making that has an important effect on their lives - in their workplace, school, local planning authority, nursing home, etc."; and (iv) standing for office, voting, and collectively participating in special-interest and public-interest associations (Ayres and Braithwaite 1995, 17).

Elaborating on top of Braithwaite's work, a related view is contended by the concept of "smart regulation", coined by Gunningham et al. (1998) for the environmental field:

The term refers to a form of regulatory pluralism that embraces flexible, imaginative and innovative forms of social control. In doing so, it harnesses governments as well as business and third parties. For example, it encompasses self-regulation and co-regulation, using commercial interests and non-governmental organisations (NGOs) (such as peak bodies) as regulatory surrogates, together with improving the effectiveness and efficiency of more conventional forms of direct government regulation. (Gunningham and Sinclair 2017, 133)

The authors try to avoid dichotomies (government/citizens, state/market...) to focus on the plurality of regulatory forms, influences, and interactions among international standards organisations, trading partners and the supply chain, commercial institutions and financial markets, peer pressure and self-regulation through industry associations, internal environment management systems, and culture (i.e.

\footnotetext{
${ }^{27} \mathrm{http}: / /$ johnbraithwaite.com/responsive-regulation/. See also Braithwaite (2017).
} 
"civil society in myriad different forms") (ibid.). This leads to different design regulatory principles: (i) preferring complementary instrument mixes over single instrument approaches, (ii) less interventionist measures, (iii) escalating responses up an instrument pyramid to build in regulatory responsiveness, (iv) empowering third parties to act as surrogate regulators, (v) encouraging business to go "beyond compliance" within existing legal requirements (ibid.). Governments should bind themselves to entice or induce rather than enforce compliance. ${ }^{28}$

Both responsive and smart approaches have eventually been considered by the European Commission when launching a better regulation planning throughout the whole European policy cycle. Table 5.3 summarises the principles:

These principles are applied through several mandatory instruments before an initiative is launched and funds are allocated: roadmaps, Impact Assessments, fitness checks, and eventually final audits. According to the Better Regulation agenda, the EU Commission should ensure that (i) decision-making is open and transparent, (ii) citizens and stakeholders can contribute throughout the policy and law-making process, (iii) EU actions are based on evidence and understanding of the impacts, (iv) and regulatory burdens on businesses, citizens or public administrations are kept to a minimum. ${ }^{29}$ Thus, responsive regulation is a way to cope with the "legitimacy market failure" as pointed out by Purnhagen $(2015,51)$ : "top-down macro-economic regulation without a social bottom-up backup by the peoples of Europe has mostly failed".

Yet, it comes with limitations. This is an administrative governance model. It aims at building a EU public space that guarantees and protects citizens' rights, but it is mainly addressed to rulers, state officials and members of public administrations. While the model encompasses individual citizens, organisations, and social groups, it does not consider putting the whole framework into their hands or lending them tools to build their own regulatory systems. In this sense, it is perhaps better to take it as it is, a useful framework, or better, a component of the European governance framework linking the macro and micro-levels of public administration.

For instance, it fosters e-participation, in EU law-making processes (Schmitz et al. 2016, 2017). However, as already shown at the level of legal interoperability, what is missing is the meso-level. If we define linked democracy as a distributed, technologically-supported collective decision-making process, what is yet to be built is the middle-ground connectivity emerging from community-building citizenry.

It is worth mentioning in this point the impulse of legal mixed public/private business models in the new Web of Data scenarios. We are thinking of the more

\footnotetext{
${ }^{28}$ Thus, "the preferred role for government under smart regulation is to create the necessary preconditions for second or third parties to assume a greater share of the regulatory burden rather than engaging in direct intervention (Gunningham and Sinclair 2017, 139).

${ }^{29} \mathrm{https}$ ://ec.europa.eu/info/law/law-making-process/planning-and-proposing-law/better-regulationwhy-and-how_en.
} 
Table 5.3 Principles of better regulation

\begin{tabular}{|c|c|}
\hline $\begin{array}{l}\text { Embedded in the planning } \\
\text { and policy cycle }\end{array}$ & $\begin{array}{l}\text { Be well-planned and timely. All the preparatory and analytical } \\
\text { work, including stakeholder consultations, must be done in time } \\
\text { to feed into the policy development process }\end{array}$ \\
\hline Of high quality & $\begin{array}{l}\text { Be of the highest quality. The basis of any stakeholder } \\
\text { consultation should be clear, concise and include all necessary } \\
\text { information to facilitate responses }\end{array}$ \\
\hline Evidence-based & $\begin{array}{l}\text { Be based on the best available evidence including scientific } \\
\text { advice, or a transparent explanation of why some evidence is } \\
\text { not available and why it is still considered appropriate to act }\end{array}$ \\
\hline $\begin{array}{l}\text { Participatory/Open to } \\
\text { stakeholders' views }\end{array}$ & $\begin{array}{l}\text { Ensure wide participation throughout the policy cycle. Open } \\
\text { web-based public consultations should be mandatory elements } \\
\text { of any consultation strategy associated with and evaluation or } \\
\text { impact assessment }\end{array}$ \\
\hline $\begin{array}{l}\text { Respect for subsidiarity and } \\
\text { proportionality }\end{array}$ & $\begin{array}{l}\text { EU action must be relevant and necessary, offer value beyond } \\
\text { what Member State action alone can deliver and not go further } \\
\text { than is necessary to resolve the problem or meet the policy } \\
\text { objective }\end{array}$ \\
\hline Comprehensive & $\begin{array}{l}\text { They must consider relevant economic, social, and } \\
\text { environmental impacts of alternative policy solutions. } \\
\text { Stakeholders' views must be collected on all key issues }\end{array}$ \\
\hline $\begin{array}{l}\text { Coherent/Conducted } \\
\text { collectively }\end{array}$ & $\begin{array}{l}\text { Be coherent. New initiatives, impact assessments, consultations } \\
\text { and evaluations must be prepared collectively by all relevant } \\
\text { services in the framework of interservice groups }\end{array}$ \\
\hline Proportionate & $\begin{array}{l}\text { Be proportionate to the type of intervention or initiative, the } \\
\text { importance of the problem or objective, and the magnitude of } \\
\text { the expected or observed impacts }\end{array}$ \\
\hline Transparent & $\begin{array}{l}\text { Be clearly visible. Results of evaluations, impact assessments } \\
\text { and consultations should be widely disseminated. Stakeholder } \\
\text { responses should be acknowledged, and consultation results } \\
\text { widely disseminated through a single access point. The reasons } \\
\text { for disagreeing with dissenting views must be explained }\end{array}$ \\
\hline Unbiased & $\begin{array}{l}\text { Be objective and balanced. They should inform political choices } \\
\text { with evidence - not the other way around }\end{array}$ \\
\hline $\begin{array}{l}\text { Appropriately resourced and } \\
\text { organised }\end{array}$ & $\begin{array}{l}\text { Be underpinned by sufficient human and financial resources to } \\
\text { enable each evaluation, impact assessment or consultation to } \\
\text { deliver a timely high-quality result }\end{array}$ \\
\hline
\end{tabular}

Source European Commission, Better Regulation Toolbox 1, Principles, Procedures \& Exceptions. https://ec.europa.eu/info/sites/info/files/file_import/better-regulation-toolbox-1_en_0.pdf, 6-7

than fifty institutes of the World Legal Information Institute, ${ }^{30}$ who have been provided with access to all kinds of legal documents since 1992 with the explicit aim of fostering the rule of law. Actually, they have been turning top-down and exclusively market-based approaches into more relational and flexible ways of

\footnotetext{
${ }^{30}$ See http://www.worldlii.org/, especially http://www.austlii.edu.au/ and https://www.law.cornell. edu/.
} 
handling regulations, services, and rights. These mixed, hybrid models will probably grow and thrive in the web of data, as they encompass a flexible way to place themselves between the market, the state, and civil society. The Declaration of Free Access to Law Movement (FALM) commits them to "provide free and anonymous public access to that information" and "do not impede others from obtaining public legal information from its sources and publishing". They recently added as an objective the "development of open technical standards". ${ }^{31}$ It is an example of an independent "connectome". The Institutes foster innovation and experimentation. ${ }^{32}$

\subsection{Governing Linked Democracy: A Socio-Cognitive Approach}

\subsubsection{A Regulatory Quadrant for the Rule of Law}

The field of Normative Multi-Agent Systems (NorMAS) was incepted to integrate and cope with the different notions of norms stemming from social, cognitive and computer sciences. It can be defined "as the intersection of normative systems and multiagent systems (MAS)" (Boella et al. 2007). ${ }^{33}$ MAS are computer systems composed of multiple interacting intelligent agents, creating contexts for autonomous artificial agents. ${ }^{34}$ Artificial Socio-cognitive systems (ASCS) contemplate this interface from a tripartite model where the affordances of the system emerge from the intersection between three dimensions - institutional, the technological and the "real world" (or social space). ${ }^{35}$ Thus, reflecting human cogency and agency in context - its 'cognitive ecology'. We will start from this same point to define legal linked data systems or, tout court, socio-legal ecosystems.

Hutchins defined cognitive ecology as "the study of cognitive phenomena in context" (Hutchins 2010, 705-6). The term points to "the web of mutual dependence among the elements of a cognitive ecosystem":

Everything is connected to everything else. Fortunately, not all connectivity is equally dense. [...]. To speak of cognitive ecology is to employ an obvious metaphor, that cognitive systems are in some specific way like biological systems. In particular, it points to the web of mutual dependence among the elements of an ecosystem. (Hutchins 2010, ibid.)

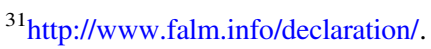

${ }^{32}$ Greenleaf (2009), Casellas et al. (2012), Greenleaf et al. (2013), Vallbé and Casellas (2014), Curtotti et al. (2015).

${ }^{33}$ See Andrighetto et al. (2013) for a general view; for norMAS and law, Casanovas et al. (2014a).

${ }^{34}$ On MAS applications see Sierra (2004), Christiaanse and Hulstijn (2012), and especially the survey carried out by Müller and Fischer (2014).

${ }^{35}$ See Noriega et al. (2014), Christiaanse et al. (2014), Christiaanse and Hulstijn (2012). In 2016, their Manifesto for conscious design introduces the notion of Hybrid Online Social Systems (HOSS) and situates them at the centre of the triangle: the impact of AI affects everyday life (Noriega et al. 2016). On the notion of 'coordination' for norMAS, see Aldewereld et al. (2016).
} 
Hutchins draws on Bateson's metaphor of the "blind man" to further illustrate his point. To explain the locomotion of a blind man with a stick, "you will need the street, the stick, the man, the street, the stick, and so on, round and round" (ibid.). The metaphor also echoes Herbert Simon's ant's path, and the second order isomorphism fallacy. ${ }^{36}$

Creating a socio-legal ecosystem requires an appraisal of the dynamic coupling between the social environment, the actors and the tools and technologies they use to reach their objectives and recreate their social bonds. It involves experimentation, plasticity and sensitivity. The outcomes of this interplay can also be conceived as thinking without representation. For example, collective action emerges from a set of conditions and coordinated actions that constitute the system, allowing multiple possibilities to deploy in one direction or another. This enaction ${ }^{37}$ perspective does not exclude the role of collective emotions in the making of regulatory schemes, as the cognitive properties of groups are different from the cognitive properties of any individual in the group.

The idea of complex intermediation is crucial to create sustainable socio-legal ecosystems on the web. Again, in the first edition of The Sciences of the Artificial (1969), Simon introduced the property of near-decomposability of systems: sub-systems can have stronger links within them than between them. The second edition (1984), which includes a new chapter on the social world, shows how coordination in a complex system is complex at every level of the system. We could benefit from these ideas, as the components of a regulatory system also exhibit the plasticity and diversity of near-decomposable systems.

When it comes to the social implementation of the rule of law-either through Artificial Socio-cognitive Technical Systems (ASCS), Hybrid Online Social Systems (HOSS), or Open Linked Data (OLD) systems - it is possible to identify basic components and the relations between them looking at the sources, domains, and position with respect to citizens (bindingness of norms or rules). Rather than discrete categories or lists of requirements, it is a matter of degree and conditions of values and principles. In a way, this is previous to building any kind of ontology or artificial tool. We are dealing with the pragmatic dimension of the rule of law, i.e. its governance.

To start with, we could figure out the implementation of the rule of law along two different relational dimensions at the empirical level: (i) material institutional power [force, macht, fuerza, forza], (ii) and social dialogue (negotiation,

\footnotetext{
${ }^{36}$ First-order isomorphism describes the situation in which a similarity relation exists between an internal representation and the real-world object being represented (Shepard and Chipman 1970). Second-order isomorphism refers to a similarity relation that exists between the similarities among internal representations and the corresponding similarities among multiple real-world objects being represented (Shepard and Chipman 1970). As famously depicted in The Sciences of the Artificial (1969), an ant, viewed as a behaving system, is quite simple. The apparent complexity of its behaviour over time is largely a reflection of the complexity of the environment in which it finds itself. Complexity is in the environment, not in the ant.

${ }^{37}$ 'Enaction' is the notion that organisms create their own experience through their actions in a dynamic and multi-modal way. We are assuming that this holds as well for social groups or communities.
} 
compromise, mediation, agreement). Thinking of law and regulations, power and how it is handled and eventually shared, matters. Even at the micro-level, the alignment of Linked Democracy properties with Ostrom's Common Pool Resources principles (Fig. 4.3) maintains a proportioned and gradual system of sanctions. There is a wide range of sanctions, from incentives to criminal punishment. But we are looking for some value to be assigned to them according to the degree of 'bindingness' of norms and the acceptance of stakeholders.

The intuition to first separate binding from non-binding norms according to the nature of the objectives and procedures is implicitly assumed by many formulations. For instance, Brous et al. (2016) produced a long list of principles for data governance in their systematic review. They eventually distilled four principles of data governance for public organizations - organisation, alignment [with the needs of the business], compliance [monitoring and enforcement], and common understanding [of data quality]. But, "data quality is often related to 'fitness for use' and data governance demands binding guidelines and rules for data quality management". Likewise, when searching for requirements for an architecture framework for pan-European E-Government services, Mondorf and Wimmer (2016) used a nuanced concept of compliance (and the bindingness of agreements). They applied the notion of "enterprise architecture", a concept used to deal with organisational complexity and interoperability. The EU Better Regulations scheme for interoperability has also been structured within this framework. The Open Group Architecture Framework (TOGAF) is developing the technical architecture to make it applicable: the EIRA legal view equally splits up legal regulations into binding and non-binding instruments. ${ }^{38}$

Figure 5.2 below plots our regulatory quadrant for the rule of law. The validity of norms (i.e. their 'legality') emerges from four different types of regulatory frames, with some distinctive properties. Properties are understood here as correlating dynamic patterns. But this is only a preliminary scheme, a conceptual compass to be used for a first clustering of norms, according to their type and degree of compliance: abidance (for hard law), conformance (for policies), accordance (for soft law), and congruence (or congruity) for ethics. According to the degree of abstraction at the implementation level, these four categories can be blurred into overlapping concepts. Agreements can be understood as mandatories; in practice, corporate policies can be more binding than some statutes. Actually, the concept of "negative compliance" or "noncompliance" is used to denote corporate strategies to avoid legal abidance when compliance is deemed to be too expensive or contrary to the business interests (Mun 2015).

\footnotetext{
38“"A [Public Policy] is the outcome of a specific [Public Policy Cycle] that aims at addressing the needs of a group of stakeholders. The policy is formulated and implemented with the help of [Public Policy Formulation and Implementation Instruments] such as [Legal Requirements or Constraints] in the form of either [Binding Instruments] or [Non-Binding Instruments], or [Operational Enablers], such as [Financial Resources] or [Implementing Guidelines]." See "Legal view" TOGAF $(2017,39)$.
} 


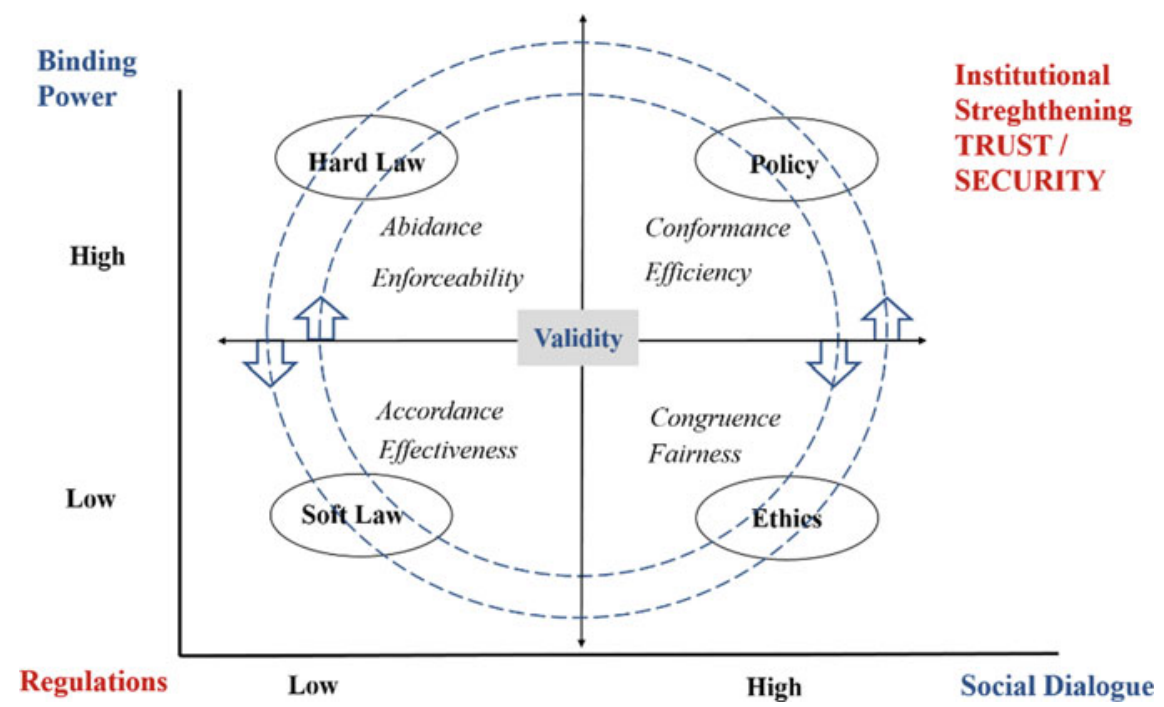

Fig. 5.2 Regulatory quadrant for the rule of law

\subsubsection{Types of Legal Governance}

Hard law refers to legally binding obligations, either in the national or international arena, under regulations that can lead to adjudication court processes. Soft law, on the contrary, is usually not mandatory. It consists of non-legally binding rules, best practices, and principles that facilitate the governance of networks, social organizations, companies, and institutions. Soft law makes room for dialogue, negotiations, and shared decisions by relevant actors and interested stakeholders. In the quadrant, soft and hard law are non-discrete categories situated on a continuum that allows the coordination of different powers and authorities to produce global law and regulations across borders involving citizens, organizations, and states (Karlsson-Vinkhuyzen and Vihma 2009).

International actors choose softer forms of legalized governance when those forms offer superior institutional solutions. [...]. The realm of soft law begins once legally arrangements are weakened along one or more of the dimensions of obligation, precision, and delegation. This softening can occur in varying degrees along each dimension and in different combinations across dimensions. We use the shorthand term soft law to distinguish this broad class of deviations from hard law - and, at the other extreme, from purely political arrangements in which legalization is largely absent. But bear in mind that soft law comes in many varieties: the choice between hard law and soft law is not a binary one (Abbot and Snidal 2000, 421-422).

As recently evaluated by D'Rosario and Zeleznikow (2018), we should not underestimate the force of soft law, as it evidences the role of market forces and bilateral and multi-lateral pressures on legal implementation. d'Aspremont et al. (2017) have also highlighted this point as a social source of International Law. 
Policy is usually defined as a "a set of ideas, or a plan of what to do in particular situations, that has been agreed officially by a group of people, a business organization, a government, or a political party." 39 It refers to policies designed, enacted, and implemented by corporations, companies, nation-states or international agencies and organisations. Policies cannot be understood as soft law when they are enacted by government agencies that have the capacity of enforcing them by means of sanctions, fines and lawsuits. There is a phenomenon of osmosis or hybridization between government administrations and agencies, and corporate governance. Government agencies tend to be drawn on corporate organisational and, especially, information and data-driven models. However, public governance is and should be kept separate from the private one (including companies and corporations).

Corporate governance is a broad category than can also be considered as a form of policy-making. It includes methodologies, models and standards developed over the last twenty-five years (for example, ISO standards related to corporate and regulatory compliance and security). Some models for IT Governance are drawn from COSO, COBIT, ISO 27002 (ISO 17799) and ISO 38500. ${ }^{40}$ There are also best practices and standards set by international professional organisations. ISO/IEC $27001^{41}$ is an information security standard published by the International Organization for Standardization (ISO) and by the International Electrotechnical Commission (IEC), entitled Information technology-Security techniques-Code of practice for information security management.$^{42}$ Standards for the representation of vocabularies on the Semantic Web have been recently considered by ISOs on thesaurus. The new ISO 25964 is close to the SKOS approach and includes a data model. It is divided into two parts: (i) Thesauri for information retrieval, (ii) Interoperability with other vocabularies. ${ }^{43}$

W3C recommendations and standards on linked open data also fall within this category (policy/governance). Developers adopting them benefit from their wide acceptance. Yet, standards are not expected to gain compliance but conformance. They refer to the quality of coding and markup tools such as Hypertext Markup

\footnotetext{
${ }^{39} \mathrm{https} / / /$ dictionary.cambridge.org/dictionary/english/policy.

${ }^{40}$ This standard is based on the AS 8015-2005 Australian Standard for Corporate Governance of Information and Communication Technology (2005).

${ }^{41} \mathrm{http} / / /$ www.iso27001 security.com/html/27002.html.

${ }^{42}$ See also (i) ISO 17799 (developed today by ISO 27001/02), a guide for implementing a set of policies, practices and procedures to consolidate the information security administered by an organization, (ii) ISO/IEC 27002, which requires that management systematically examines the organization's information security risks, taking account of the threats, vulnerabilities and impacts; (iii) Clause 6.1.3 of ISO/27001:2013, describes how an organisation can respond to risks with a risk treatment plan; an important part of this is choosing appropriate controls; (iv) ISO/IEC 27002 seeking the preservation of confidentiality, integrity, and availability.

${ }^{43}$ ISO 25964: Information and documentation-Thesauri and interoperability with other vocabularies. See the presentation by the project lead (Clarke and Stella 2011).
} 
Language (HTML) and Cascading Style Sheets (CSS) and allow validators to check the conformance of web coding to them. ${ }^{44}$

Both ISO/IECs and W3C standards can be conceived as forms of soft law, network or multi-stake holder governance. Yet, these latter concepts have a broader regulatory scope, intended to solve political and social disputes in regional, national, and international arenas (e.g. conflicts between social groups, corporations, companies, sub-state and state entities).

We can consider different types of governance that would fall under the policy label-mainly internet, network, ${ }^{45}$ stakeholder, ${ }^{46}$ data, and algorithmic governance. ${ }^{47}$ Cap 1 has briefly presented some of them. Data and algorithmic governance are especially relevant to expand the protections of the rule of law.

We should differentiate Internet governance from the forms of contemporary governance on the web. The latter has been increasingly introduced through the combination of algorithms, semantic languages, computational linguistics, data mining, ${ }^{48}$ visualization, and, recently, Artificial Intelligence methods (such as deep machine learning). ${ }^{49}$ They are ambiguously referred to as "big data" 50 Some prudence is required here: after their extended review, Sivarajah et al. $(2017,279)$ conclude that strengthening empirical research based on in-depth case studies, and qualitative and quantitative research, is much needed as "most of the articles analysed followed an analytical approach".

A functional typology of algorithmic selection applications is offered by Just and Latzer (2017): (i) search, (ii) aggregation, (iii) surveillance, (iv) forecast, (v) filtering, (vi) recommendation, (vii) scoring, (viii) content production, (ix) and allocation. Each one of them constitute separate domains of computer expertise, understood as a governance "institutional steering", a "horizontal and vertical extension of traditional government", looking beyond public and private actors (e.g. governments and industry) and, vertically, looking beyond multi-stakeholder instruments. Social reality is now increasingly shaped and constructed by algorithmic selection (ibid.).

\footnotetext{
${ }^{44}$ http://validator.w3.org/, http://jigsaw.w3.org/css-validator/.

${ }^{45}$ Rhodes (2007), Provan and Kenis (2008), Gottschalk (2009).

${ }^{46}$ On the notion of 'stake-holder governance', Hens and Bhaskar (2005); on its structure and processes applied to the Internet, Malcolm (2008, 2015); on "stake-holder democracy", MacDonald (2008), MacDonald and MacDonald (2017); for a critical view see Bäckstrand (2006), Fransen and Kolk (2007), Bexell et al. (2010).

${ }^{47}$ Cfr. The surveys by Chen and Zhang (2014), Siddiqa et al. (2016); cfr. also, on algorithmic governance, the typology by Just and Latzer (2017).

${ }^{48}$ I.e. Correlation and regression analysis; and data classification, clustering, prediction, and diagnosis (Zhao-Hong et al. 2018, 205)

${ }^{49}$ See the surveys on data-intensive applications (Chen and Zhang 2014), big data life-cycles and management (Khan et al. 2014) big data management (Siddiqa et al. 2016), big data analytics in governance (Bhardwaj and Singh 2017), on data processing methods (Zhao-Hong et al. 2018).

${ }^{50}$ It is commonly described as data satisficing a 5-V model: (i) Volume (data scale datasets), (ii) Value (low density, high value information), (iii) Variety (including unstructured and semi-structured data), (iv) Velocity (speed of data collection and analysis), (v) Validity (quality and veracity of data).
} 
Thus, the problem is now how to assemble, monitor, use and control these different methods. Semantic matching to identify related information, re-engineering, re-using, model-driven engineering and graph analysis operating on an ontological basis are some of the techniques that the semantic web community is developing. Smart data is related to the 5-V model (see note 113): "an organized way to semantically compile, manipulate, correlate, and analyse different data sources" (Duong et al. 2017) that is adding value to governance and decision-making. From a regulatory point of view, there are several challenges related to them: security and data protection, ownership, privacy, data flows exchange and cross-border data flows. After the enactment of the European GDPR this is a hot topic, with countless contributions.

We would like to point out just one challenge that is key to the linked democracy approach. In Table 5.1 we aligned Ostrom's CPR principles - rules in use matched to local needs and conditions, participation, self-monitoring, need of proportional sanctions...-with the substantive principles of the rule of law. This is a new version of the so-called micro-macro link problem. Ostrom's principles are community-driven. How could polycentric governance be compatible with data-driven societies? Pitt et al. $(2013,40)$ contend that

Collective awareness can be achieved by analysing big data generated by networked sensors and devices as well as ICT-enabled users. Search, data mining, and visualization technologies make it possible to spot trends and predict the trajectories of higher-level variables. This in turn enables collective action, without which it might be impossible to change community behaviour to reach a desirable outcome-for example, sustaining a scarce resource.

Social intelligence, collective action modelling entails a shift both in governance and legal studies. Our contention is that collective awareness can also be carried out within the framework of the meta-rule of law.

Finally, Ethics primarily refer to morals, social mores, practical knowledge and principles that should be implemented into legal regulations, policies, and governance structures. But, most interestingly, ethics can be infused across them. ${ }^{51}$

Ethics and law were not mentioned in the first accounts on the semantic web (e.g. Bizer et al. 2011), but this is experiencing a dramatic turn. The defence of ethical values embedded into computer systems, Multi-Agent Systems (MAS) and Artificial Intelligence is a hot topic now, bringing together (i) thoroughness (the sound implementation of what the system is intended to do), (ii) mindfulness (those aspects that affect the individual users, and stakeholders) and (iii) responsibility (the values that affect others) (Noriega et al. 2016).

\footnotetext{
${ }^{51}$ We can identify schematically at least four stages in privacy and data protection related to ethical principles. This is a well-known history: (i) the inception of Fair Information Practice Principles (FIPs) that were published in 1973 by the Advisory Committee on Automated Personal Data Systems in the Department of Health, Education and Welfare (USA) under the inspiration of Alan Westin; (ii) the proposal of a unifying identity metasystem layer by the Microsoft Chief Architect Kim Cameron in his blog in 2005; (iii) the proposal of Privacy-by-design principles ( $\mathrm{PbD}$ ) issued by Ann Cavoukian in 2006; (iv) the development of $\mathrm{PbD}$ and by default in the General Data Protection Reform launched by the EU in 2012 that led to the new EU Regulation that came into force in May 2018.
} 
The Onlife Manifesto (Floridi 2015) reflects on the fading distinction between reality, virtuality, human, machine, and nature that seems to be prevalent in our hyperconnected world. The authors elaborate on the notion of complexity (see Pagallo 2015; Pagallo et al. 2018) and MAS to question (or nuance) the role of the nation-state in web of data environments.

Dignum (2018) has shown that ethics and AI are related at several levels: (i) Ethics-by-Design (EbD, "the technical/algorithmic integration of ethical reasoning capabilities as part of the behaviour of artificial autonomous system"), (ii) Ethics-in-Design (EiD, "the regulatory and engineering methods that support the analysis and evaluation of the ethical implications of AI systems as these integrate or replace traditional social structures"), (iii) and Ethics-for-Design (EfD, "the codes of conduct, standards and certification processes that ensure the integrity of developers and users as they research, design, construct, employ and manage artificial intelligent systems").

We also deem all three levels necessary to implement the principles of the rule of law beyond the boundaries of the nation state and to develop socio-legal ecosystems.

\subsection{Governing Linked Democracy: Socio-Legal Ecosystems}

\subsubsection{Socio-Legal Ecosystems}

The term 'ecosystem', coined by Arthur Tansley in 1935, originated in biology and ecology studies. In ecology, the term points to the coexistence of living and non-living organisms in a niche, or "integration of all biological (biotic) and nonbiological (abiotic) parts" and "monitoring the movement of energy and materials (water, chemicals, nutrients, pollutants, etc.) into and out of its boundaries" (Vogt et al. 1997, 71). The concept was later adopted, among many other disciplines, by cybernetics, meaning the interface and exchange of information in complex systems within their environments (i.e. within social and natural contexts). Gregory Bateson entitled the collection of his works Towards an Ecology of Mind (1972). This is the tradition we choose to situate our own use of the term, familiar to cognitive sciences and cognitive ecology, along with 'situated meaning' and 'situated cognition'.

The notion of 'legal ecosystem' has also been recently used in professional studies, referring to the involvement of all legal professionals and stakeholders (Brenton 2017). In computer sciences and law, it has been employed to wrap up the methodology that involves the participation of end-users in the knowledge acquisition process (Governatori et al. 2009). We will use the notion of 'legal linked data ecosystm' or, tout court, 'socio-legal ecosystem' in a different way, meaning all processes, interactions and exchange of information involved in the social and 
cultural implementation of a regulatory system, including its design, monitoring, and users' compliance and behaviour. We will point out the dynamic properties of its normative elements and its institutional settings.

If we assume the essential socio-cognitive framework described above, it appears that we cannot generate a legal ecosystem by just laying down, enacting, or publishing a law or regulation in an official site. In most cases of public law, this can be considered a necessary non-sufficient condition. Nevertheless, the system should also be understood, accepted, and settled under the social conditions that guarantee its implementation. We contend that legal ecosystems are not just generated from the enactment of laws: they emerge from a set of conditions amongst human and technical interactions, including the requirements of artificial systems and the individual and collective behaviour of their users.

Zuiderwijk et al. (2014) have suggested a number of actions and four key elements when building Open Data (OD) ecosystems: (i) releasing and publishing open data on the internet, (ii) searching, finding, evaluating and viewing data and their related licenses, (iii) cleansing, analysing, enriching, combining, linking and visualizing data, and (iv) interpreting and discussing data and providing feedback to the data provider and other stakeholders. To integrate the full set of required elements they add three additional elements: (v) user pathways showing directions for how open data can be used, (vi) a quality management system and (vii) different types of metadata to be able to connect the elements. Thus, an OD ecosystem consists of a multilayered and plural framework: (i) "an open data ecosystem is characterized by multiple interdependent socio-technical levels, dimensions, actors (including data providers, infomediaries and users), elements and components", and (ii) "need to address challenges related to policy, licenses, technology, financing, organization, culture, and legal frameworks and are influenced by ICT infrastructures" (Zuiderwijk et al. 2014, 29-30).

However, to turn these kind of OD ecosystems into legal ones, we should delineate more precisely how all these elements can be related to the whole regulatory system (not only to the type of license at stake) and to agency. Hence, we would need to articulate a scheme (or meta-model) that could be used (i) to flesh out the three dimensions plotted in Fig. 10 (legal, social and semantic), (ii) to differentiate the properties of the regulatory system and the meta-rule scheme for the rule of law, (iii) to embed privacy/data/security and compliance by-design into computer systems, (iv) to situate and implement them into specific environments, (iv) and to embed the protections of the rule of law into the meta-rule of law through formal representations of norms and rights. All components, functions and activities that the construction of an OD ecosystem entails should be evaluable and evaluated.

Moreover, social ecosystems are complex, and micro-agent interaction and change can lead to a macro-system evolution (Mitleton-Kelly and Papaefthimiou 2002). Some feed-back processes are associated with them. In the case of the rule of law, both positive and negative feedback are present: the goal of producing trust and security through institutional strengthening mechanisms tends to create stability, which is one of the features to make a socio-legal ecosystem sustainable; but the whole process is not teleologically-driven, i.e. some changes in the system are 
not intended. Socio-legal systems are cultural, in a broad sense. Thus, "a plethora of interacting and interconnected micro-feedback-processes whose connectivity and interaction creates emergent macro-feedback-processes and structures" (Mitleton-Kelly and Papaefthimiou 2002, 272). Excessive control mechanisms and inflexible rule-driven organisations can be counterproductive.

Figures 5.3, 5.4 and 5.5 are complementary. The first one is Braithwaite-like, similar to the pyramids for regulatory theory (responsive and smart regulations) drawn by Braithwaite, Gunningham, Grabosky and Sinclair, among others (Drahos 2017). We used an almost identical one to plot the levels of "formality" in mediation: from implicit to explicit dialogue, and from non-binding law to binding law (Casanovas et al. 2011, Intr.). Processes and outcomes could be accommodated into it, from natural mediation to legal mediation. Interestingly enough, this could illuminate the artificial model to support mediation that Noriega et al. (2011) articulated as an electronic institution, as the problem that emerged out of it was the legal value of the agreement. When can an artificially-driven procedure 'count as' legal? When can procedural moves through different steps be considered as 'legal'?

Artefacts and e-institutions are tools, and as such can be used informally as well. Only when the e-institution is nested into a social set of relationships that assert the degree and value of its "affordances"-the effectiveness and efficiency of its internal moves and steps in a given environment - the outcome can hold not only as formally or 'normatively' valid, but as 'legally' valid as well. The term 'affordance' is an interesting concept. It denotes the properties of the environment that are perceived, endorsed and eventually modified by the agents' actions. From this perspective, the 'validity' ('legality') of a right, norm, or a set of norms can be understood as a complex outcome of the affordances of the system.

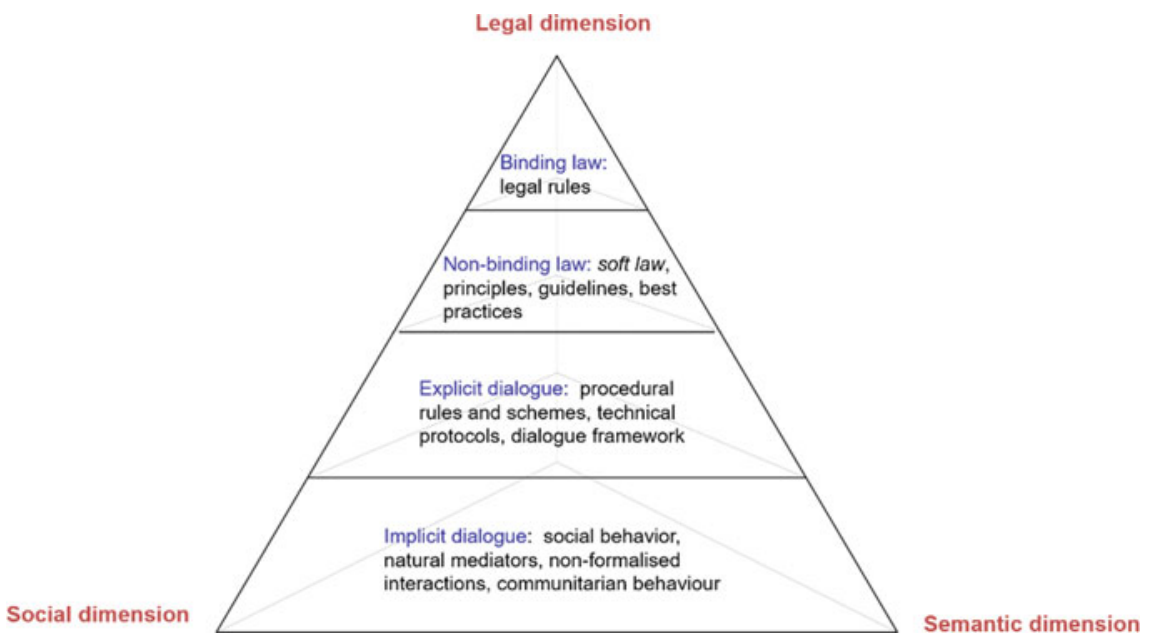

Fig. 5.3 From social informal dialogue to legal formal power 


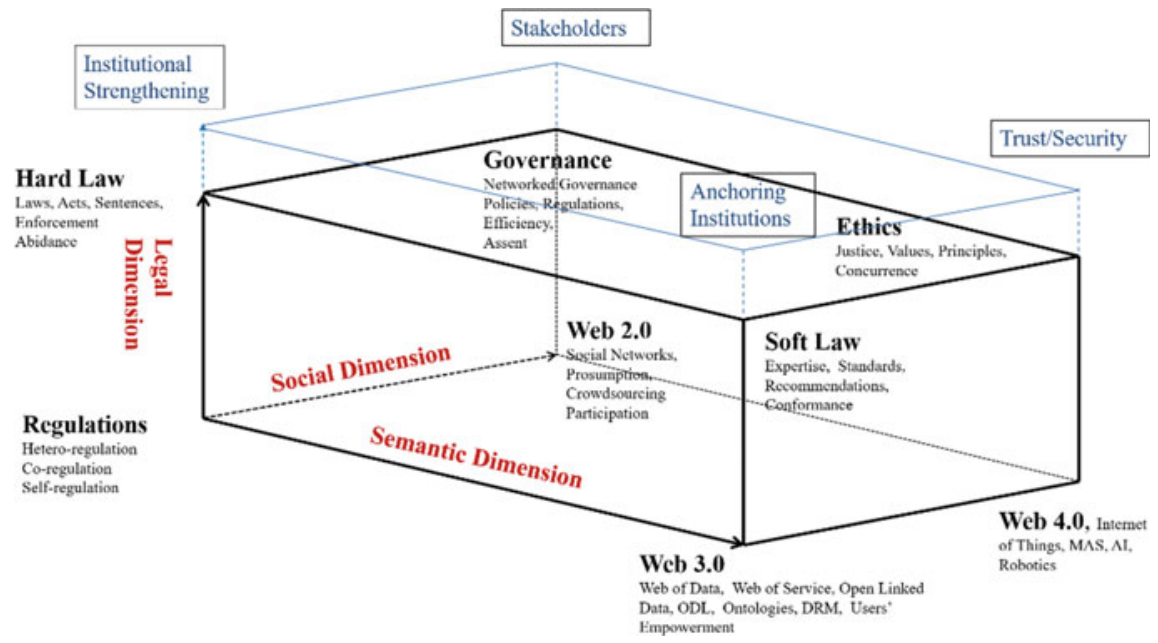

Fig. 5.4 Socio-legal ecosystems pragmatic layer

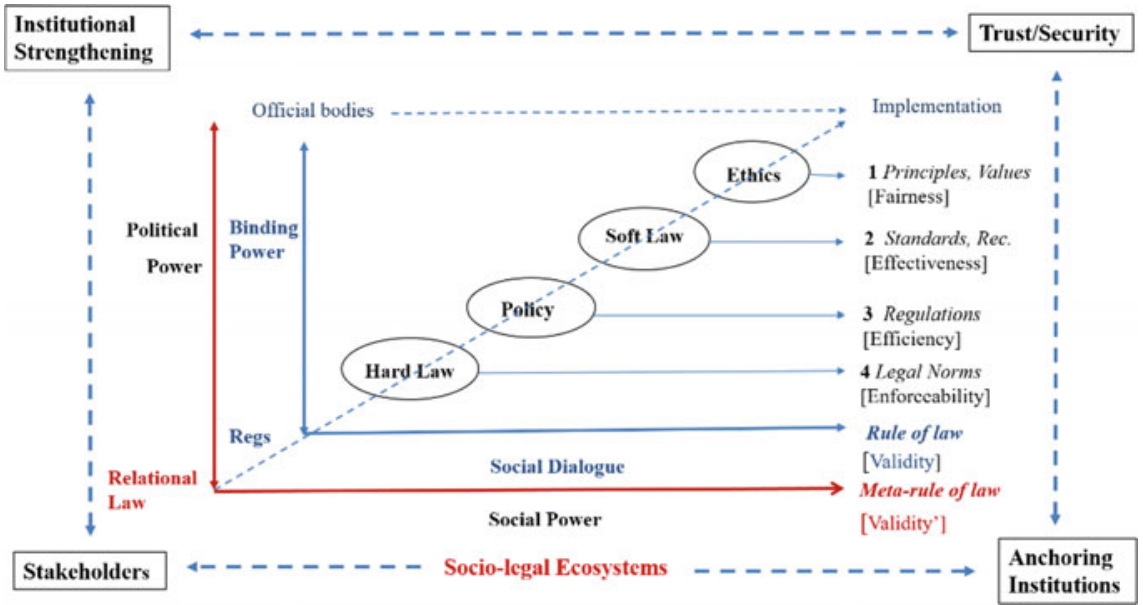

Fig. 5.5 Meta-model for socio-legal ecosystems (Meta-rule of law)

\subsubsection{A Meta-Model for the Implementation of the Rule of Law}

Thus, the problem for validity is not just that the collective processes coming from the grassroots, bottom-up, should be "legally" compliant with norms to also acquire a legal value, but that legality itself might show different values and degrees of accomplishment. 
'Validity' [Geltung, validez, validità, validité] is defined in analytical theory as the property which captures for any rule or norm the quality of belonging to a legal system. Usually, a 'valid' norm is deemed to be a 'legal norm'. And, to acquire this quality of law, a rule or norm is expected to be (or become) valid. ${ }^{52}$ In legal theory, the definition has recently turned from a conception in which validity was considered as a feature of norms or system of norms to a discursive one, in which the law comes into being by means of the argumentation process stemming from them (legal argumentation) (Grabowski 2013). This is partially leaning on previous works on defeasible logic and argumentation by H. Prakken and G. Sartor, among others, drawing an inferential theoretical approach to legal systems in wich rules are understood as 'inferential links'. 53

We deem our approach compatible with a normative, discursive or logical definition of validity (Araszkiewicz and Casanovas 2016). Validity in these latter senses refers to the regulatory model built by the analyst, i.e. it holds for the regulatory model that it is built as discourse, reasoning, argumentation or knowledge; but to make it 'legal', i.e. admissible, requires the satisfaction of another set of conditions that are depending on the contextual field of application and on the regulatory sources at hand. From this standpoint, validity depends upon other properties - i.e. affordances — running along two different axes (binding power, social dialogue), and it emerges as a property from the functioning of the whole system (including human and artificial agents). Regulations unfold along an institutional continuum. Validity is a characteristic feature of such a continuum, a property pertaining and emerging from the whole regulatory system which is essentially dynamic and related to the interactive behaviour of agents. From this standpoint, it does not 'supervene', but 'emerges' once first order propertiesenforceability, efficiency, effectiveness, and fairness (criteria for justice) - reach a pre-determined threshold. Hence, what becomes gradually 'valid' is the whole system, as the actual presence (as a fact) of its components make it happen (in many ways). This is close to the idea of pragmatic web advanced by Singh (2002a) in the early days of the Semantic Web: "semantics in a manner that is reusable across applications, the priority of process over data, the importance of interaction, and the critical need for accommodating user context" (Singh 2002b). ${ }^{54}$

\footnotetext{
${ }^{52}$ We will follow up here the discussion initiated in Casanovas (2012), and followed in Casanovas (2015a, b, 2017) and Araszkiewicz and Casanovas (2016). An early example, Casanovas et al. (2006).

${ }^{53}$ Sartor (2009a) contends that 'intermediate legal concepts' (such as 'property') are the concepts through which legal norms convey both legal consequences and preconditions of further legal effects. In Sartor (2009b) he contends that there is a tension between their inferential and ontological meaning, and that both sides are required to make sense of legal norms.

${ }^{54}$ See the Pragmatic Web Manifesto (Schoop et al. 2006), and our position in Casanovas et al. (2017a).
} 
Figure 5.4 represents the necessary meta-level that can be added on top of Fig. 5.1 to ground validity on the three regulatory dimensions of the Web-legal, social and linguistic. Figure 5.5 depicts the meta-model we propose to cope with this complexity.

We are facing hybrid environments, partly human, and partly created by artificial agents or languages (linked data). To operationalise a regulatory system, to integrate its three dimensions into a specific environment and make it 'legal', we need to figure out some more elements: (i) the institutional strengthening of some type of positive law or rights; (ii) the behaviour of stakeholders (creating, using, and participating proactively in its creation, modification and eventual substitution); (iii) the production of security and trust (as a result: they are never directly produced but reached); (iv) the presence of intermediate institutions created to "anchor" the properties of the system - i.e. its affordances - into the social space.

From an empirical point of view, 'validity' can be conceptually defined as a second order property, a four-tuple function of ethics (fairness), policies (efficiency), soft law (effectiveness) and hard law (enforceability), emerging from the ecosystem. This definition facilitates the application of metrics to measure the institutional strengthening of the system; i.e. the coordinated organization of normative components for specific platforms, apps or other devices applying semantic technologies. We do not yet have a composite indicator for legal validity (i.e. for assigning legality) - just a preliminary attempt (Ciambra and Casanovas 2014) but it would be useful for assessing the legal value of the strength, scope and performance of the regulatory system.

Figure 5.5 provides more perspectives on the components and the layered dynamics of the meta-model. Within this approach, several levels of 'validity' can be distinguished: (a) validity as a product of the official norms enacted by an official body (this is the classical definition); (b) as the composite product of official norms, multi-layered stakeholder governance, negotiations (dialogue), and ethics (values); (c) as the product of the internal process of rule-representation in some formal language (legalXML, legalRuleML) - meta-rule of law-; (d) as the social regulatory product within the socio-legal ecosystem. Let's call them (i) positive validity; (ii) composite validity; (iii) formal validity; (iv) and ecological validity.

Ecological validity is a popular term in psychology. It refers to the extent the results of the research can be linked or referred to predict behaviour and situations in everyday life (i.e. in different contexts and scenarios). Aaron Cicourel cautions that it can only be approximated in the social and behavioural sciences. ${ }^{55}$ Our use of the term refers to the extent a normative system or regulatory model is anchored and institutionalised within a specific legal ecosystem. In this sense, it relates to the way that abidance, accordance, conformance and congruence with norms are

\footnotetext{
55"Validity in the non-experimental social sciences refers to the extent to which complex organizational activities represented by aggregated data from public and private sources and demographic and sample surveys can be linked to the collection, integration, and assessment of temporal samples of observable (and when possible recordable) activities in daily life settings." (Cicourel 2007, 736)
} 
effectively materialized, and the affordances that the regulatory system puts into play and offers to the (human or artificial) agents, depending on how it has been designed.

Recent research on the semantic relationships established by Hohfeld - the eight "jural" relationships included into the two classical squares of opposites and correlatives ${ }^{56}$ - has shown that they can be remodelled using Petri nets. ${ }^{57}$ They can be conceptualised from an interactional perspective. This leads to the idea of understanding the environment and the intentions of action (they can be negative as well) to set the position and roles of players (as the authors say, a scheme of a seem-to-be normal sale may hide a money-laundering scheme). Rights and duties are referred to this semantically enriched patterns to start modelling, i.e. to embed more complex specific situations into a formal representation language.

This is a good place to recall Ostrom's design principles for sustainable management (CPR). Pitt and Diaconescu (2015) apply the idea of complex intermediate autonomous sub-systems to develop the polycentricism of governance in self-organised institutions. ${ }^{58}$ For example, when considering the possibility to set communities that control their own energy infrastructure, Pitt and Diaconescu (2015) note that excessive demand, which would otherwise lead to a power outage, could be pre-empted with co-dependent institutions that use social capital to stabilise their inter-operations. However, they also observe that rules alone are not enough to implement it:

Co-dependence between socio-technical systems with shared resources implies that such systems cannot run in isolation and follow completely independent rule sets. Indeed, co-dependence requires coordination via dedicated institutions, the management of which is critical to the sustainability and endurance of the resulting system of co-dependent systems.

In this case, the ecological validity of the system depends on how well the institutional coordination of the co-dependence works. But there are many other situations in which the focal point, i.e. the salient features of the outcome that produces coordination ${ }^{59}$, will be related to sanctions, motivation, understanding or habit of the members of the community (Gunderson and Cosens 2018). Behavioural compliance and ecological validity are closely related (Casanovas and Oboler 2018).

\footnotetext{
${ }^{56}$ I Jural Opposites: Right/No Right; Privilege/Duty; Power/Disability; Immunity/Liability. II Jural Correlatives: Right/Duty; Privilege/No-right; Power/Liability; Immunity/Disability.

${ }^{57}$ Sileno (2016, 161 and ff.), Sileno et al. (2014, 2015).

${ }^{58}$ Pitt and Diaconescu draw from Koestler's notion of 'holon' (something that is simultaneously a whole and a part): "a holonic system (or holarchy) is composed of "a holonic system (or holarchy) is composed of interrelated subsystems, each of which are in turn composed of sub-subsystems and so on, recursively, until reaching a lowest level of 'elementary' subsystems" (ibid.).

${ }^{59}$ We borrow the use of the term 'salience' and 'focal point' from McAdams and Nadler (2008).
} 


\subsubsection{Semantic Web Regulatory Models (SWRM)}

The meta-model depicted in Fig. 5.5 allows the assessment of 'legality' or 'validity' to embed the protections and values of the rule of law into modelling- SW languages, NorMAS, ASCS. To regulate processing and the outcomes of an information system on a platform, e.g., several sources are usually used at different dimensions and levels of organization. Take privacy, for instance. It begins to take shape in the semantic field (Kirrane et al. 2018). There is a pool of norms coming from different organisms and settings, including statutes, case law, policies, standards, best practices... Norms are not just there: they are first selected, interpreted, constructed, combined and eventually implemented by means of a set of intermediary processes into regulatory models. Moreover, to ingrain legal rights into computer models, a process of correlating and mapping design strategies, e.g. against privacy and data protection patterns, must be put in place.

Working on the modelling strategy, Colesky and Ghanavati (2016) have proposed to add a further level of abstraction that they define as tactic. Strategy "specifies a distinct architectural goal in privacy by design to achieve a certain level of privacy protection", while tactics is "an approach to privacy by design which contributes to the goal of an overarching privacy design strategy". Therefore, in the line of goal-oriented requirements engineering, they flesh out the "quality attribute" for privacy strategies regarding data, i.e. (i) enforce, (ii) demonstrate, (iii) control, (iv) inform, (v) minimise, (vi) abstract, (vii) separate, (viii) and hide. This is related to semantic compliance.

There are at least three ways to embed Privacy by Design (PbD) into modelling (design planning): (i) direct strategy (compliance by design, as it was classically understood by Cavoukian), (ii) tactics (near compliance, as defined by Colesky and Ghavanati (2016) and (iii) indirect strategy (compliance through design). The notion of 'near compliance' reflects the difficulties of modelling legal rights: "software designed with compliance in mind from the beginning, resulting in less legal consultant work". The notion of 'compliance through design' tries to encompass not only legal requirements but the systemic interoperability that is needed to model affordances and socio-legal conditions.

An indirect strategy is subjected to some more requirements, as it embraces a pragmatic approach. It comprises the information flow, the organisation, the functions and affordances of the technological device, the roles of designers, controllers and end-users, including lawyers or consultants that participate all along the process, in which ontology building is one of the components to enhancing and implementing rights (Casanovas et al. 2014b). Thus, semantic interoperability is one of the objectives to be reached, but legal compliance is deemed to have a 
deeper and larger scope than regulatory compliance. Compliance-by design $(\mathrm{CbD})$ and Compliance-through design (CtD) can be distinguished according to the structure, components, and the nature of their effects. ${ }^{60}$

This is especially relevant for the implementation of the meta-rule of law, because the way that rights (and especially political rights) are defined sets a normative and institutional framework in which all citizens exercise and perform their freedom and specific liberties. These liberties have a transnational and global scope and have been conceptualised in a number of political philosophies. We have recently summarised their ethical scope in four dimensions, elaborating on Walzer's, Nussbaum's, and Floridi's formulations: (i) complex equality (justice could be adjudicated across distinct distributive spheres, in order to respect the differences and harmonise social goods, wealth, political office, commodities, education, security, health...), (ii) contextual integrity (adequate selection and enactment of rights to norms of specific contexts) (iii) ontology (not to be confused with computer ontologies, it refers to fundamental ethical concepts), (iv) and algorithmic governance. By doing this, we intended to address the bases for setting the relationships between linked democracy and the meta-rule of law (Casanovas et al. 2017b).

We will stress now that to foster socio-legal ecosystems related to linked democracy we should rely both on infrastructures, programs and artificial tools, and on the legal instruments and models to develop better and smart stakeholder governance. Responsive law is still an ideal. Linked democracy, as it has been presented in previous chapters, is a way to organise knowledge, institutions, and people to foster interoperability, remove silos, and create a secure framework for data sharing. We have already shown (ibid. 2017, Poblet et al. 2017) that it might operate to frame the connection between expert, collective, and personal knowledge in public health, allowing and empowering people to manage their own medical Electronic Health Records (EHRs) (also referred to as Medical Health Records $[\mathrm{MHR}]$ ) in a safe and efficient way. However, as Robert Mathews has reminded in his introductory article for a Health \& Technology special issue on privacy and medicine, "privacy desperately needs a common language, and a universal frame of reference, but it lacks for one" (Mathews 2017, 268). Well: the same is needed for the rule of law. We desperately need a lingua franca, a reliable meta-rule of law with a global scope, but we lack for one.

The distinction between normative Semantic Web Regulatory Models (nSWRM) and institutional Semantic Web Regulatory Models (iSWRM) (Casanovas 2015a, b) is relevant here. The former ones are based on semantic languages, encompassing almost exclusively inferential tools and RDF, RuleML SPARQL, OWL (among many other languages). In this sense, implementation is not a modelling priority. Digital Rights Management (DRM), Rights Expression Languages (REL), machine processable languages for the expression of licenses, such Open Digital Rights languages (ODRL) constitute privileged examples: the ODRL Core Model was

\footnotetext{
${ }^{60}$ See the recent surveys on business process regulatory compliance (Hashmi et al. 2018a), and on legal compliance (Casanovas et al. 2017c), Hashmi et al. (2018b) .
} 
designed "to be independent from implementation" (2009). ${ }^{61}$ But this is not the same for iSWRM. Conversely, they need to be much more attentive to the community of users and their organisations. iSWRM allow people to communicate, interact, share and set self-regulated collectives for specific purposes. They help to rebuild, maintain and change social bonds. Regulations applicable to platforms addressing e-learning, e-health, disaster management, crisis-mapping, or political participation are some examples. Terminologies (multi-lingual term banks), cotrolled vocabularies and content-related thesauri help implementing this institutional dimension of regulatory models (Rodríguez-Doncel et al. 2016).

However, this is not an absolute distinction, for institutions and norms are built alike and they often constitute distinctive sides of the same socio-legal ecosystem. Would it be possible to speak of personal ecosystems? For example, when I make a personal use of a Creative Commons license, should I be considered a member, element or component of the CC ecosystem? According to the organisation, there is an affirmative answer for this question:

Initially we define the ecosystem as the network in which CC operates. Creative Commons often must respond to events over which we have little control or influence. These events arise from the fields of technology, society and non-users of CC licenses, and economic, regulatory and environmental influences. $\mathrm{CC}$ exerts some control and influence over licensing of digital content; users of CC licenses, our Affiliates and the digital commons, and the technical infrastructure we use. $\mathrm{CC}$ has a high degree of control over our internal processes, how we communicate and promote our work and our suppliers. ${ }^{62}$

This means equating ecosystems with the performance and scope of social networks. Our use of the term in a broad sense can also encompass this version, as this is referred to as the implementation of codes, rules and principles empowering the user and having an impact on her behaviour. It empowers the user to choose and select the framework she wants for labelling and managing her personal content on the web. But the regulation itself is not institutionally-driven. It does not create and manage the public identity for the user. The user does.

An institutionally-driven model instead focuses on the identity of the social group that creates or uses the tool as a sufficient condition to constitute the institution. It intends to mainly set up a structured environment for the community or social group that comes up as a result of its inception.

\subsection{Conclusions and Future Work}

In this chapter, (i) we have presented innovative forms of governance, (ii) advanced a set of minimal conditions for the rule of law on the web; (iii) introduced some of the requirements for legal interoperability, (iv) and proposed a conceptual scheme to frame socio-legal ecosystems.

\footnotetext{
${ }^{61}$ https://www.w3.org/2012/09/odrl/archive/odrl.net/2.0/DS-ODRL-Model-20090923.html.

${ }^{62} \mathrm{https}: / /$ wiki.creativecommons.org/wiki/Research.
} 
The thread that runs through the entire chapter is that the rule of law can work as the general and global framework that gets together some regulatory instruments that have commonly been kept disjointed-national, international and responsive law; policy, and better, smart and data governance; semantic web languages, and algorithmic governance.

The rule of law constitutes an ideal yet to be developed for the web of linked data. Let's be reminded of the W3C five-star principles for the web: (i) make your stuff available on the web under an open license; (ii) make it available as structured data; (iii) make it available in a non-proprietary open format; (iv) use URIs to denote things; (v) link your data to other data to provide context. ${ }^{63}$

The notion of linked democracy embraces them, but it should provide the adequate protections and incentives to foster them safely and appropriately. Berners-Lee blogged in 2009: "It's not the Social Network sites that are interesting - it is the Social Network itself. The Social Graph. The way I am connected, not the way my Web pages are connected." He called it the Giant Global Graph.

This is implicitly echoing the same problems encountered by political philosophers in the 16th and 17th centuries. It reminds another, less gentle, artificial giant. If we don't want to go back to the contractual notions of covenant, pact and delegation of power, we should be able to come up with some notions to empower and protect people and enhance their rights. The notions of meta-rule of law and sustainable socio-legal ecosystems point at the way we all should be connected. The link between the individuals and the collective.

The quadrant we have drawn (hard law, policy, ethics and soft law) can be used as a sort of regulatory quadrant for the sources of the rule of law. But this is an idealization: regulations at the implementation level are hybrid; they encompass norms, principles and values from all sections. Likewise, institutions connecting linked data with people, platforms and ecosystems can be built in many different ways. They set up a hybrid public space, between the market, the state and civil society - a relational notion of law, in which rights and duties can be assigned with different degree of compliance and enforcement.

The four notions of validity introduced in this chapter are related to legal governance. They can be used for different purposes. Positive validity is often assumed by semantic web developers as an ontological commitment. Formal validity refers to the internal consistency of models. Once established as a reasonable threshold (this would be a golden rule), composite validity can be used for evaluating the legal compliance of platforms focusing on their informational flows. This can be done independently of their aims and objectives - political crowdsourcing, crisis and disaster management, or security and open source intelligence. Ecological validity refers to the creation of legal linked data ecosystems by institutional means, i.e. through shared systemic (not just semantic) interoperability building. Compliance through Design (CtD) is one of the conceptual ways we can follow to set a reliable institutional framework.

\footnotetext{
${ }^{63}$ https://5stardata.info/en/.
} 
$\mathrm{CtD}$ can be operationalised at different social, legal, and jurisdictional levels. For example, to enhance bottom-up participation (Karamagioli et al. 2017; Poblet 2018), or to link the rule of law to constitutional rights on specific national grounds. At that level, the ideas of open access and open constitutional courts (Keyzer 2010) are close to open rights and linked open data ecosystems. They can be readjusted to the dimensions of the next stages of the web illustrated in Figs. 5.2 and 5.3.

From a theoretical point of view, our conceptualization has two important political consequences. The first one is that within the web of data, 'legality' cannot be taken as the result of the activity of official representatives, the judiciary, government members and state agencies in a national state, alone. In a linked democracy model, legality comes from the grassroots as well, and it can be the result of the interaction of agents (all kind of agents: human and artificial, individual and collective) that respect the rule of law. It is a collaborative endeavour.

The meta-model has a second consequence. If these distinctions make any sense, it is not necessary to keep the sharp Weberian divide between legitimacy and legality; i.e. the strict separation between the ground of the political system (e.g. based on a majority rule) and its development through a legal autonomous system. Democracy and legality are intertwined. In this way, democracy is not deemed to be just a political form that shapes constitutions and laws, but a process to organise innovative and shared knowledge that empowers individuals, i.e. people, at a global level on the web.

\section{References}

Abbott KW, Snidal D (2000) Hard law and soft law in international governance. International Organization. Summer 54(3):421-456. https://doi.org/10.1162/002081800551280

Abel RL (2018) Law's wars: The fate of the rule of law in the US 'war on terror'. Cambridge University Press, UK

Aldewereld H, Boissier O, Dignum V, Noriega P, Padget JA (eds) (2016) Social coordination frameworks for social technical systems, LGTS, vol 30. Springer, Dordrecht. https://doi.org/10. 1007/978-3-319-33570-4

Andrighetto G, Governatori G, Noriega P, van der Torre LW (2013) Normative multi-agent systems, vol 4. Schloss Dagstuhl-Leibniz-Zentrum für Informatik

Araszkiewicz M, Casanovas P (2016) On legal validity. In: Hoekstra R (ed) JURIX 2016, Legal knowledge and information systems, vol 294. IOS Press, Amsterdam, pp 125-130

Athan T, Governatori G, Palmirani M, Paschke A, Wyner AZ (2014) Legal interpretations in LegalRuleML. In: CEUR 1296, SW4LAW + DC@ JURIX

Athan T, Governatori G, Palmirani M, Paschke A, Wyner A (2015) LegalRuleML: Design principles and foundations. In: Faber W., Paschke A. (eds) Reasoning Web. Web Logic Rules. Reasoning Web 2015. Lecture notes in computer science, 9203:151-188. Springer, Cham

Ayres I, Braithwaite J (1995) Responsive regulation: transcending the deregulation debate. Oxford University Press

Bäckstrand K (2006) Democratizing global environmental governance? Stakeholder democracy after the World Summit on Sustainable Development. Eur J Int Relat 12(4):467-498. https:// doi.org/10.1177/1354066106069321

Bhardwaj A, Singh W (2017 Dec) Systematic review of big data analytics in governance. In 2017 international conference on intelligent sustainable systems (ICISS). IEEE, pp 501-506 
Balke T, da Costa Pereira C, Dignum F, Lorini E, Rotolo A, Vasconcelos W, Villata S (2013) Norms in MAS: definitions and related concepts. In: Dagstuhl follow-ups (4). Schloss Dagstuhl-Leibniz-Zentrum für Informatik

Bench-Capon TJM, Coenen FP (1992) Isomorphism and legal knowledge based systems. Artif Intell Law 1(1):65-86. https://doi.org/10.1007/BF00118479

Bench-Capon TJM, Gordon TF (2009) Isomorphism and argumentation. In: Proceedings ICAIL '09, ACM, New York, pp 1-20. https://doi.org/10.1145/1568234.1568237

Bexell M, Tallberg J, Uhlin A (2010) Democracy in global governance: the promises and pitfalls of transnational actors. Glob Gov 16(1):81-101. https://doi.org/10.4103/cs.cs_15_104

Bizer C, Heath T, Berners-Lee T (2011) Linked data: the story so far. In: Semantic services, interoperability and web applications: emerging concepts IGI Global, p. 2015-227

Boella G, van der Torre L, Verhagen H (2007) Normative multi-agent systems. In: Dagstuhl seminar proceedings 07122, Internationales Begegnungs- und Forschungszentrum für Informatik (IBFI), Schloss Dagstuhl, Germany

Boella G, Tosatto SC, Ghanavati S, Hulstijn J, Humphreys L, Muthuri R, Rifaut A, van der Torre L (2014) Integrating legal-URN and Eunomos: towards a comprehensive compliance management solution. In: Casanovas P et al (eds) AI approaches to the complexity of legal systems, AICOL 2013. LNCS 8929. Springer, Berlin, pp 130-144

Boer AWF (2009) Legal theory, sources of law and the semantic web. IOS Press, Amsterdam. https://doi.org/10.3233/978-1-60750-003-2-i

Braithwaite J (2017) Types of responsiveness. In: Drahos P (ed) Regulatory theory: foundations and applications. ANU Press, Canberra, pp 117-132

Brenton C (2017) CLOC: joining forces to drive transformation in legal: bringing together the legal ecosystem. In: Liquid Legal Springer, Cham, 2003-2010

Brous P, Janssen M, Vilminko-Heikkinen R (2016) Coordinating decision-making in data management activities: a systematic review of data governance principles. International conference on electronic government and the information systems perspective. Springer, Cham, pp 115-125

Carothers T (1998) The rule of law revival. Foreign Aff 77(2):95-106. https://doi.org/10.2307/ 20048791

Casanovas P, Casellas N, Vallbé JJ, Poblet M, Benjamins VR, Blázquez M, Peña R, Contreras J (2006) Semantic web: a legal case study. In: Davis J, Studer R, Warren P (ed) Semantic web technologies: trends and research. Ed. Wiley, Chichester, pp 259-280

Casanovas P (2012) A note on validity in law and regulatory systems. Quaderns de filosofia i ciència 42:29-40

Casanovas P (2013) Agreement and relational justice: a perspective from philosophy and sociology of law. In: Ossowski S (ed) Agreement technologies. Springer, Dordrecht, pp 17-41

Casanovas P (2017) Sub Lege Pugnamus. De la Gran Guerra a les Grans Dades. Publicacions de la Universitat de Barcelona, Barcelona

Casanovas P (2015a) Conceptualisation of rights and meta-rule of law for the web of data, Democracia Digital e Governo Eletrônico (Santa Caterina, Brazil) 12, 18-41; repr. J Gov Regul 4(4):118-129

Casanovas P (2015b). Semantic web regulatory models: why ethics matter. Philos Technol. Special Issue on Inform Soc Ethical Inq 28(1):33-35. https://doi.org/10.1007/s13347-014-0170-y

Casanovas P, Lauroba E, Magre J (2011) Introducción. In: Casanovas P, Lauroba E, Magre J (eds), Libro Blanco de la Mediación en Cataluña. Generalitat de Catalunya, Ed. Huygens, Barcelona, pp 173-178

Casanovas P, Oboler A (2018) Behavioural compliance and law enforcement in online hate and fear speech, TERECOM 2018, technologies for regulatory compliance. In: Proceedings of the 2nd workshop on technologies for regulatory compliance co-located with the 31 st international conference on legal knowledge and information systems (JURIX 2018) Groningen, The Netherlands, pp 125-134. http://ceur-ws.org/Vol-2309/11.pdf

Casanovas P, Palmirani M, Pagallo U, Sartor G (2014a) Law, social intelligence, nMAS and the semantic web: an overview. In: Casanovas P et al (ed) AI approaches to the complexity of legal systems IV. Social intelligence, models and applications for law and justice systems in the semantic web and legal reasoning. LNAI 8929. Springer, Heidelberg, pp 1-10 
Casanovas P, Arraiza J, Melero F, González-Conejero J, Molcho G, Cuadros M (2014b) Fighting Organised Crime through Open Source Strategies: Regulatory Strategies of the CAPER Project. Legal knowledge and information systems. In: Hoekstra R (ed) JURIX 2014: the twenty-seventh annual conference, Foundations on artificial intelligence n. 271, IOS Press, Amsterdam, pp 189-199

Casanovas P, Palmirani M, Peroni S, van Engers T, Vitali F (2016) Semantic web for the legal domain: the next step. Semantic Web 7(3):213-227. https://doi.org/10.3233/SW-160224

Casanovas P, Rodríguez-Doncel V, González-Conejero J (2017a) The role of pragmatics in the web of data. In: Capone A, Poggi F (eds) Pragmatics and law. Practical and theoretical perspectives. Springer, Dordrecht, Heidelberg, pp 293-330

Casanovas P, Mendelson D, Poblet M (2017b) A linked democracy approach for regulating public health data. Health Technol 7(4):519-537

Casanovas P, Gonzalez-Conejero J, de Koker L (2017c) Legal compliance by design (LCbD) and through design (LCtD): preliminary survey. In: TERECOM. Proceedings of the 1st workshop on technologies for regulatory compliance co-located with the 30th international conference on legal knowledge and information systems (JURIX 2017), CEUR 2049, pp 33-49

Casellas N, Bruce TR, Frug S, Bouwman S, Dias D, Lin J, Marathe S, Rai K, Singh A, Sinha D, Venkataraman S (2012) Linked legal data: improving access to regulations. In: Proceedings of the 13th annual international conference on digital government research (DGO 2012), ACM, New York, US, 2012, pp 280-281. https://doi.org/10.1145/2307729.2307785

Celino I, Corcho O, Hölker F, Simperl E (2018) Citizen science: design and engagement (Dagstuhl seminar 17272). In: Dagstuhl reports 7(7). Schloss Dagstuhl-Leibniz-Zentrum fuer Informatik

Cicourel AV (2007) A personal, retrospective view of ecological validity. Text Talk 27(5-6):735752. https://doi.org/10.1515/TEXT.2007.033

Ciambra A, Casanovas P (2014) Drafting a composite indicator of validity for regulatory models and legal systems. In: Casanovas P, Palminari M, Pagallo U, Sartor G (eds) AI approaches to the complexity of legal systems IV. Social intelligence, models and applications for law and justice systems in the semantic web and legal reasoning, LNAI 8929, Springer, pp 70-82

Chen CP, Zhang CY (2014) Data-intensive applications, challenges, techniques and technologies: a survey on big data. Inf Sci 275:314-347

Cheesman N (2015) Opposing the rule of law. How Myanmar courts make law and order. Cambridge University Press

Christiaanse R, Ghose A, Noriega P, Singh MP (2014) Characterizing artificial socio-cognitive technical systems. In: Herzig A, Lorini E (eds) Proceedings of the European conference on social intelligence (ECSI-2014), Barcelona, Spain, 3-5 Nov 2014. CEUR workshop proceedings, 1283, pp 336-346

Christiaanse R, Hulstijn J (2012) Control automation to reduce costs of control. International conference on advanced information systems engineering. Springer, Berlin, pp 322-336

Clarke SGD, Stella G (2011) ISO 25964: a standard in support of KOS interoperability. In: Facets of knowledge organization: proceedings of the ISKO UK second biennial conference, 4-5 July 2011, London, pp 129-134

Colesky M, Ghanavati S (2016) Privacy shielding by design-a strategies case for near-compliance. In: Requirements engineering conference workshops (REW), IEEE International, pp 271-275

Corcho O, Poveda-Villalón M, Gómez-Pérez A (2015) Ontology engineering in the era of linked data. Bull Assoc Inform Sci Technol 41(4):13-17

Curtotti M, McCreath E, Bruce T, Frug S, Weibel W, Ceynowa N, Weibel W (2015) Machine learning for readability of legislative sentences. In: Proceedings of the 15th international conference on artificial intelligence and law, ACM, New York, pp 53-62

d'Aquin M, Motta E, Sabou M, Angeletou S, Gridinoc L, Lopez V, Guidi D (2008) toward a new generation of semantic web applications. IEEE Intell Syst 23(3):20-28. https://doi.org/10. 1109/MIS.2008.54

d'Aspremont J, Besson S, Knuchel S (eds) (2017) The sources of International law: an introduction. In: The Oxford handbook of the sources of International law. Oxford University Press, Oxford, pp 1-39 
Dignum V (2018) Ethics in artificial intelligence: introduction to the special issue. Ethics Inform Technol 20:1-3. https://doi.org/10.1007/s10676-018-9450-z

Drahos P (ed) (2017) Regulatory theory: foundations and applications. ANU Press, Canberra

Domingue J, d'Aquin M, Simperl E, Mikroyannidis A (2014) The web of data: bridging the skills gap. IEEE Intell Syst 29(1):70-74

D'Rosario M, Zeleznikow J (2018) Compliance with International soft law: is the adoption of soft law predictable? Int J Strateg Decis Sci (IJSDS) 9(3):1-15

Duong TH, Nguyen HQ, Jo GS (2017) Smart data: where the big data meets the semantics. Comput Intell Neurosci

Erlanger H, Garth B, Larson J, Mertz E, Nourse V, Wilkins D (2005) Is it time for a new legal realism. Wisconsin Law Rev 2:335-363

Floridi L (ed) (2015) The onlife manifesto. Being human in an hyper-connected era. Springer, Dordrecht

Fransen LW, Kolk A (2007) Global rule-setting for business: a critical analysis of multi-stakeholder standards. Organization 14(5):667-684. https://doi.org/10.1177/ 1350508407080305

Feigenbaum EA (1984) Knowledge engineering: the applied side of artificial intelligence (1982). Ann N Y Acad Sci 426:91-107

Francesconi E, Küster MW, Gratz P, Thelen S (2015) The ontology-based approach of the publications office of the EU for document accessibility and open data services. In: Kö A, Francesconi E (eds) International conference on electronic government and the information systems perspective, EGOVIS-2015. Springer, LNCS, Cham, pp 29-39

Garner JH, Hickman MJ, Malega RW, Maxwell CD (2018) Progress toward national estimates of police use of force. PLoS ONE 13(2):e0192932

Gel'man V (2004) The unrule of law in the making: the politics of informal institution building in Russia. Eur-Asia Stud 56(7):1021-1040

Ginsburg T, Tamir M (2008) Rule by law: the politics of courts in authoritarian regimes. Cambridge University Press, Cambridge

Gordon TF, Governatori G, Rotolo A (2009) Rules and norms: requirements for rule interchange languages in the legal domain. In: Governatori G, Hall J, Paschke A (eds) International workshop on rules and rule markup languages for the semantic web. LNCS 5858. Springer, Berlin, pp 282-296

Gottschalk P (2009) Maturity levels for interoperability in digital government. Gov Inform Q 26:75-81. https://doi.org/10.1016/j.giq.2008.03.003

Governatori G, Indulska M, Zu Muehlen M (2009) Formal models of business process compliance. JURIX, Rotterdam

Greenleaf G (2009) AustLII's business models: Constraints and opportunities in funding free access to law. In: Peruginelli G, Ragona M (eds) Free access, quality information, effectiveness of rights. Publishing Academic Press, Florence, Italy, pp 423-436

Greenleaf G, Mowbray A, Chung P (2013) The meaning of free access to legal information: a twenty year evolution. SSRN Electron J. https://doi.org/10.2139/ssrn.2158868

Grabowski A (2013) Juristic concept of the validity of statutory law. A critique of contemporary legal nonpositivism. Springer, Dordrecht

Gunderson L, Cosens B (2018) Case studies in adaptation and transformation of ecosystems, legal systems, and governance systems. In: Cosens B, Gunderson L (eds) Practical panarchy for adaptive water governance. Springer, Cham

Gunningham N, Grabosky P, Sinclair D (1998) Smart regulation: designing environmental policy. Oxford University Press, Oxford

Gunningham N, Sinclair D (2017) Smart regulation. In P. Drahos (ed) Regulatory theory. Foundations and applications, Canberra, ANU Press, pp 133-148

Hashmi M, Governatori G, Lam HP, Wynn MT (2018a) Are we done with business process compliance: state of the art and challenges ahead. Knowl Inf Syst 57(1):79-133

Hashmi M, Casanovas P, de Koker L (2018b) Legal compliance through design: preliminary results, TERECOM 2018. Technologies for regulatory compliance, In: Proceedings of the 2nd workshop on technologies for regulatory compliance co-located with the 31 st international 
conference on legal knowledge and information systems (JURIX 2018) Groningen, The Netherlands, pp 59-72. http://ceur-ws.org/Vol-2309/06.pdf

Hens L, Bhaskar N (2005) The world summit on sustainable development: the Johannesburg conference. Springer, Dordrecht

Hoekstra R (2009) Ontology representation design patterns and ontologies that make sense. IOS Press, Amsterdam

Hoekstra R (2010) The knowledge reengineering bottleneck. Semant Web 1(1, 2):111-115

Hutchins E (1995) Cognition in the wild. The MIT Press, Cambridge Mass.

Hutchins E (2006) The distributed cognition perspective on human interaction. In: Tomasello M, Enfield N, Levinson SC (eds) Roots of human sociality: culture, cognition and interaction 1. Berg Publishers, Oxford, pp 375-398

Hutchins E (2010) Cognitive ecology. Top Cogn Sci 2(4):705-715

Just N, Latzer M (2017) Governance by algorithms: reality construction by algorithmic selection on the Internet. Media Cult Soc 39(2):238-258. https://doi.org/10.1177/0163443716643157

Khan N, Yaqoob I, Hashem IAT, Inayat Z, Ali M, Kamaleldin W, Alam M, Shiraz M, Gani A (2014) Big data: survey, technologies, opportunities, and challenges. Sci World J

Karamagioli E, Karatza M, Xydia S, Gouscos D (2017) Participatory constitutional design: a grassroots experiment for (re) designing the constitution in Greece. In: Paulin A et al (eds) Beyond bureaucracy. Towards sustainable governance informatisation. Springer, Dordrecht, pp 151-166

Karlsson-Vinkhuyzen S, Vihma A (2009) Comparing the legitimacy and effectiveness of global hard and soft law: an analytical framework. Regul Gov 3:400-420

Keyzer P (2010) Open constitutional courts. The Federation Press, Annandale

Kirrane S, Villata S, d'Aquin M (2018) Privacy, security and policies: a review of problems and solutions with semantic web technologies. Semant Web 9:153-161. https://doi.org/10.3233/ SW-180289

Koops BJ, Leenes R (2014) Privacy regulation cannot be hardcoded. A critical comment on the 'privacy by design' provision in data-protection law. Int Rev Law, Comput Technol 28(2):59-171

Koops BJ, Newell BC, Timan T, Skorvanek I, Chokrevski T, Galic M (2016) A typology of privacy. U Pa J Int L 38:483-575

Kun L, Beuscart R, Coatrieux G, Quantin C, Mathews R (2008) Improving outcomes with interoperable EHRs and secure global health information infrastructure. In: Bos L et al (eds) Medical and care compunetics 5. IOS Press, Amsterdam, pp 68-79

Lam HP, Hashmi M, Scofield B (2016) Enabling reasoning with LegalRuleML. International symposium on rules and rule markup languages for the semantic web. Springer, Heidelberg, pp 241-257

Li Y (2012) Theories in online information privacy research: a critical review and an integrated framework. Decis Support Syst 54(1):471-481. https://doi.org/10.1016/j.dss.2012.06.010

Van Lamsweerde A (2001) Goal-oriented requirements engineering: a guided tour. In: Requirements engineering, 2001. Fifth IEEE international symposium on requirements engineering. IEEE Comput Soc:249-261. https://doi.org/10.1109/isre.2001.948567

van Lamsweerde A (2009) Requirements engineering: from system goals to UML models to software, vol 10. Wiley, Chichester, UK

Macaulay S (2005) The new versus the old legal realism: things ain't what they used to be. Wisconsin Law Rev 2:365-403

Macdonald T (2008) Global stakeholder democracy: power and representation beyond liberal states. Oxford University Press

Macdonald K, Macdonald T (2017) Liquid authority and political legitimacy in transnational governance. Int Theor 9(2):329-351. https://doi.org/10.1017/S1752971916000300

Malcolm J (2008) Multi-stakeholder governance and the internet governance forum. Terminus Press, Perth

Malcolm J (2015) Criteria of meaningful stakeholder inclusion in internet governance. Internet Policy Rev 4(4). https://doi.org/10.14763/2015.4.391

Mathews R (2017) Interrogating 'privacy' in a world brimming with high political entanglements, surveillance interdependence \& interconnections. Health Technol 7(4):265-324. https://doi. org/10.1007/s12553-017-0211-5 
McAdams RH, Nadler J (2008) Coordinating in the shadow of the law: two contextualized tests of the focal point theory of legal compliance. Law Soc Rev 42(4):865-898

Merry SE (2017) What is the rule of law? Perspectives from Myanmar: commentary on opposing the rule of law: how myanmar's courts make law and order by nick cheesman. Hague J Rule Law 9(1):11-14. https://doi.org/10.1007/s40803-016-0041-y

Mondorf A, Wimmer MA (2016) Requirements for an architecture framework for Pan-European e-government services. In Scholl H et al (eds) Electronic government. EGOVIS 2016. LNCS 9820. Springer, Cham, pp 135-150

Motta E (2013) 25 years of knowledge acquisition. Int J Hum-Comput Stud Arch 71(2):131-134. https://doi.org/10.1016/j.ijhcs.2012.11.002

Miles TJ, Sunstein CR (2008) The new legal realism. Univ Chicago Law Rev 75(2):831-851

Mitleton-Kelly E, Papaefthimiou MC (2002) Co-evolution of diverse elements interacting within a social ecosystem. In: Henderson P (ed) Systems engineering for business process change: new directions. Springer, London, pp 253-273

Müller JP, Fischer K (2014) Application impact of multi-agent systems and technologies: a survey. In: Shehory O, Sturm A (eds) Agent-oriented software engineering. Springer, Berlin, pp 27-53

Mun E (2015) Negative compliance as an organizational response to legal pressures: the case of Japanese equal employment opportunity law. Soc Forces 94(4):1409-1437

Nonet P, Selznick P (1978) Law and society in transition: toward responsive law. Octagon Books, NY

Nourse V, Shaffer G (2009) Varieties of new legal realism: can a new world order prompt a new legal theory? Cornell L Rev 95:61-138

Noriega P, López de Toro C, Montero R, Pérez Martínez (2011) Anexo: Prototipo de un Sistema Genérico de Apoyo a la Mediación. In: Casanovas P, Lauroba E, Magre J (Dirs.) Libro Blanco de la Mediación en Cataluña. Generalitat de Catalunya, Ed. Huygens, Barcelona, pp 985-1008

Noriega P, Padget J, Verhagen H, d'Inverno M (2014) The challenge of artificial socio-cognitive systems. COIN@AAMAS 2014, Paris

Noriega P, Verhagen H, d'Inverno M, Padget J (2016) A manifesto for conscientious design of hybrid online social systems. Coordination, organizations, institutions, and norms in agent systems XII. Springer, Cham, pp 60-78

Pagallo U (2015) Good onlife governance: on law, spontaneous orders, and design. In: Floridi L (ed) The onlife manifesto. Springer, Cham, pp 161-177

Pagallo U, Palmirani M, Casanovas P, Sartor G, Villata S (eds) (2018) Introduction: legal and ethical dimensions of AI, NorMAS, and the web of data. In: AI approaches to the complexity of legal systems. AICOL international workshops 2015-2017: AICOL-VI@JURIX 2015, AICOL-VII@EKAW 2016, AICOL-VIII@JURIX 2016, AICOL-IX@ICAIL 2017, and AICOL-X@JURIX 2017, Revised selected papers. LNAI 10791. Springer, Cham, pp 1-20

Palmirani M, Paschke A, Athan T (2012) 1. Isomorphism. June 29th, oasis-open.org

Palombella G (2009) The rule of law beyond the state: failures, promises, and theory. Int J Const Law 7(3):442-467. https://doi.org/10.1093/icon/mop012

Palombella G (2010) The rule of law as and institutional ideal. In: Morlino L, Palombella G (eds) Rule of law and democracy: inquiries into internal and external issues, vol 115. Brill, London, pp 1-38

Pitt J, Bourazeri A, Nowak A, Roszczynska-Kurasinska M, Rychwalska A, Santiago IR, Sanchez ML, Florea M, Sanduleac M (2013) Transforming big data into collective awareness. Computer 46(6):40-45

Pitt J, Diaconescu A (2015, July) Structure and governance of communities for the digital society. In: Autonomic computing (ICAC), 2015 IEEE international conference on autonomic computing. IEEE, pp 279-284

Poblet M (2018) From open to crypto: horizontal, distributed, privacy-enhancing technologies for civic and political action. In: 25 world conference of political science, Brisbane, 21-24 July

Poblet M, Casanovas P, Plaza E (2017) Linked democracy: artificial intelligence for democratic innovation, LINKDEM, In: Proceedings of the Workshop on Linked Democracy: Artificial intelligence for democratic innovation co-located with the 26th International joint conference on artificial intelligence (IJCAI 2017). http://ceur-ws.org/Vol-1897/ 
Pollock R (2013) Forget big data, small data is the real revolution d open knowledge foundation blog. http://blog.okfn.org/2013/04/22/forget-big-datasmall-data-is-the-real-revolution/ (consultation: 22 Aug 2018)

Provan KG, Kenis P (2008) Modes of network governance: structure, management, and effectiveness. J Public Adm Res Theor 18:229-252

Purnhagen K (2015) Why do we need responsive regulation and behavioural research in EU internal market law? In K. Mathis (ed), European perspectives on behavioural law and economics, Cham, Springer, pp 51-69

Rhodes RA (2007) Understanding governance: ten years on. Organ Stud 28(8):1243-1264

Rodríguez-Doncel V, Santos C, Casanovas P, Gómez-Pérez A (2015) A linked term bank of copyright-related terms. JURIX 2015, Legal knowledge and information systems. IOS Press, Amsterdam, pp 91-100

Rodriguez-Doncel V, Santos C, Casanovas P, Gomez-Perez A (2016) Legal aspects of linked data - the European framework. Comput Law Secur Rev 32(6):799-813. https://doi.org/10.1016/j. clsr.2016.07.005

Sartor G (2009a) Understanding and applying legal concepts: an inquiry on inferential meaning. In: Hage JC, von der Pfordten D (eds) Concepts in law. Springer, Dordecht, pp 35-54

Sartor G (2009b) Legal concepts as inferential nodes and ontological categories. Artif Intell Law 17(3):217-251. https://doi.org/10.1007/s10506-009-9079-7

Schmitz P, Francesconi E, Batouche B, Dombrovschi B, Duy D, Landercy SP, Parisse V (2016) Linked open data and e-participation in the EU law-making process. In: Kö A, Francesconi E (eds) International conference on electronic government and the information systems perspective, EGOVIS-2016. Springer, Cham, pp 79-89

Schmitz P, Francesconi E, Landercy SP, Batouche B, Touly V (2017) A knowledge organization system for e-participation in law-making. In: Proceedings of the 16th edition of the international conference on artificial intelligence and law, ACM, pp 245-248

Schoop M, Moor AD, Dietz JL (2006) The pragmatic web: a manifesto. Commun ACM 49(5):75-76

Selznick P (2003) Law in context' revisited. J Law Soc 30(2):177-186. https://doi.org/10.1111/ $1467-6478.00252$

Shadbolt N, Hampson R (2018) The digital ape: how to live (in peace) with smart machines. Scribe Publications, Melbourne and London

Shepard RN, Chipman S (1970) Second-order isomorphism of internal representations: shapes of states. Cogn Psychol 1:1-17. https://doi.org/10.1016/0010-0285(70)90002-2

Siddiqa A, Hashem IAT, Yaqoob I, Marjani M, Shamshirband S, Gani A, Nasaruddin F (2016) A survey of big data management: taxonomy and state-of-the-art. J Netw Comput Appl 71:151166. https://doi.org/10.1016/j.jnca.2016.04.008

Sileno G (2016) Aligning law and action, Doctoral dissertation, Ph. D. thesis, University of Amsterdam

Sileno G, Boer A, van Engers TM (2014) On the interactional meaning of fundamental legal concepts. In: Sileno G, Boer A, van Engers TM (eds) Proceedings of the 27th international conference on legal knowledge and information systems (JURIX 2014). Front Artif Intell Appl, vol 271. IOS Press, Amsterdam, pp 39-48. https://doi.org/10.3233/978-1-61499-468-8-39

Sileno G, Boer A, van Engers $T$ (2015) Commitments, expectations, affordances and susceptibilities: towards positional agent programming. In: Chen Q, Torroni P, Villata S, Hsu J, Omicini A (eds) PRIMA 2015: principles and practice of multi-agent systems: 18th international conference, Bertinoro, Italy, LNAI vol 9387. Springer, Cham, pp 687-696. https://doi.org/10.1007/978-3-319-25524-8_52

Sierra C (2004) Agent-mediated electronic commerce. Auton Agent Multi-Agent Syst 9(3):285301. https://doi.org/10.1023/B:AGNT.0000038029.82331.c0

Simon HA $(1969,1984,1986)$ The sciences of the artificial. The MIT Press

Singh MP (2002a) The pragmatic web. IEEE Internet Comput 3:4-5

Singh MP (2002b) The pragmatic web: preliminary thoughts. In: Proceedings of the NSF-OntoWeb workshop on database and information systems research for semantic web and enterprises, pp 82-90

Sivarajah U, Kamal MM, Irani Z, Weerakkody V (2017) Critical analysis of big data challenges and analytical methods. J Bus Res 70:263-286 
Taylor S, Boniface M (2017) HUB4NGI:: D2. 1 NGI guide V1

Tamanaha BZ (2004) On the rule of law: history, politics, theory. Cambridge University Press

Tamanaha BZ (2009) A concise guide to the rule of law. In: Walker et al (eds) Florence workshop on the rule of law. Hart Publishing Company, St. John's Legal Studies Research Paper No. 07-0082

Tamanaha BZ (2011) The rule of law and legal pluralism in development. Hague J Rule Law 3 (1):1-17. https://doi.org/10.1017/S1876404511100019

Troullinou P, d'Aquin M, Tiddi I (2018) Re-coding black mirror chairs' welcome \& organization. In: Companion of the the web conference 2018 on the web conference 2018. International World Wide Web Conferences Steering Committee, pp 1527-1528

TOGAF (2017) An introduction to the European interoperability reference architecture (EIRAC) v2.1.0

Taylor V (2017) Regulatory rule of law. In: Drahos P (ed) Regulatory theory: foundations and applications. ANU Press, Canberra, pp 393-413

Uildriks N (2010) Mexico's unrule of law: implementing human rights in police and judicial reform under democratization. Lexington Books, Lanham

Union European (2017) New European interoperability framework promoting seamless services and data flows for European public administrations. Publications Office of the European Union, Luxembourg. https://doi.org/10.2799/78681

Vallbé J, Casellas N (2014) What's the cost of e-access to legal information? a composite indicator. In: Doing business research conference: past, present, and future of business regulation, McDonough School of Business, Georgetown University, Washington, DC, 20-21 Feb

Vogt KA, Gordon JC, Wargo JP, Vogt DJ, Asbjornsen H, Palmiotto PA, Clark HJ, O'Hara JL, Keeton WS, Patel-Weynand T, Witten E (1997) Ecosystem concept: historical and present review of definitions and development of ecosystem ecology, ecosystem management, and its legal framework. In: Vogt KA et al (eds) Ecosystems. Springer, New York, pp 13-114

Wyner A, Governatori G (2013) A study on translating regulatory rules from natural language to defeasible logic. In: RuleML 2013: the 7th international web rule symposium, held 11-13 July 2013, in Seattle, Washington, USA

Xu LD, Xu EL, Li L (2018) Industry 4.0: state of the art and future trends. Int J Prod Res 56 (8):2941-2962. https://doi.org/10.3233/ip-140329

Zhao-Hong Y, Hui-Yu W, Bin Z, Zhi-He H, Wan-Lin L (2018, April) A literature review on the key technologies of processing big data. In: 2018 IEEE 3rd international conference on cloud computing and big data analysis (ICCCBDA). IEEE, pp 202-208

Zuiderwijk A, Janssen M, Davis C (2014) Innovation with open data: essential elements of open data ecosystems. Inform Polity 19(1, 2):17-33

Open Access This chapter is licensed under the terms of the Creative Commons Attribution 4.0 International License (http://creativecommons.org/licenses/by/4.0/), which permits use, sharing, adaptation, distribution and reproduction in any medium or format, as long as you give appropriate credit to the original author(s) and the source, provide a link to the Creative Commons license and indicate if changes were made.

The images or other third party material in this chapter are included in the chapter's Creative Commons license, unless indicated otherwise in a credit line to the material. If material is not included in the chapter's Creative Commons license and your intended use is not permitted by statutory regulation or exceeds the permitted use, you will need to obtain permission directly from the copyright holder.

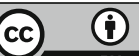

